OPEN ACCESS

Edited by:

Alexandre Heeren,

Harvard University, USA

Reviewed by:

Valentin Flaudias,

CHU Clermont-Ferrand, France

Elisabeth Colon,

Boston Children's Hospital - Harvard

Medical School, USA

*Correspondence:

Alessandra Simonelli

alessandra.simonelli@unipd.it

Specialty section: This article was submitted to

Psychopathology,

a section of the journal

Frontiers in Psychology

Received: 11 February 2016 Accepted: 30 May 2016

Published: 16 June 2016

Citation:

Parolin M, Simonelli A, Mapelli D,

Sacco M and Cristofalo P (2016)

Parental Substance Abuse As an Early

Traumatic Event. Preliminary Findings

on Neuropsychological and

Personality Functioning in Young Drug

Addicts Exposed to Drugs Early.

Front. Psychol. 7:887.

doi: 10.3389/fpsyg.2016.00887

\section{Parental Substance Abuse As an Early Traumatic Event. Preliminary Findings on Neuropsychological and Personality Functioning in Young Drug Addicts Exposed to Drugs Early}

\author{
Micol Parolin ${ }^{1}$, Alessandra Simonelli ${ }^{1 *}$, Daniela Mapelli ${ }^{2}$, Marianna Sacco ${ }^{1}$ and \\ Patrizia Cristofalo ${ }^{3}$ \\ ${ }^{1}$ Department of Developmental Psychology and Socialization, University of Padova, Padua, Italy, ${ }^{2}$ Department of General \\ Psychology, University of Padova, Padua, Italy, ${ }^{3}$ Therapeutic Community "Villa Renata", Venice, Italy
}

Parental substance use is a major risk factor for child development, heightening the risk of drug problems in adolescence and young adulthood, and exposing offspring to several types of traumatic events. First, prenatal drug exposure can be considered a form of trauma itself, with subtle but long-lasting sequelae at the neuro-behavioral level. Second, parents' addiction often entails a childrearing environment characterized by poor parenting skills, disadvantaged contexts and adverse childhood experiences (ACEs), leading to dysfunctional outcomes. Young adults born from/raised by parents with drug problems and diagnosed with a Substance Used Disorder (SUD) themselves might display a particularly severe condition in terms of cognitive deficits and impaired personality function. This preliminary study aims to investigate the role of early exposure to drugs as a traumatic event, capable of affecting the psychological status of young drug addicts. In particular, it intends to examine the neuropsychological functioning and personality profile of young adults with severe SUDs who were exposed to drugs early in their family context. The research involved three groups, each consisting of 15 young adults (aged 18-24): a group of inpatients diagnosed with SUDs and exposed to drugs early, a comparison group of non-exposed inpatients and a group of non-exposed youth without SUDs. A neuropsychological battery (Esame Neuropsicologico Breve-2), an assessment procedure for personality disorders (Shedler-Westen Assessment Procedure-200) and the Symptom CheckList-90-Revised were administered. According to present preliminary results, young drug addicts exposed to drugs during their developmental age were characterized by elevated rates of neuropsychological impairments, especially at the expense of attentive and executive functions (EF); personality disorders were also common but did not differentiate them from non-exposed youth with SUDs. Alternative multi-focused prevention and intervention programs are needed for children of drug-misusing parents, addressing EF and adopting a trauma-focused approach.

Keywords: trauma, exposure to drugs, drug-addicted youth, executive function, personality disorder 


\section{INTRODUCTION}

\section{The Extent of the Phenomenon}

Substance Use Disorders are characterized by a cluster of cognitive, behavioral and physiological symptoms indicating that individuals continue using the substance despite it causes clinically and functionally significant impairment. A diagnosis of Substance Use Disorder is based on evidence of impaired control, social impairment, risky use, and pharmacological criteria (APA, 2013). Substance disorders related to alcohol and illegal drugs implicate particularly severe clinical conditions and constitute the focus of the present study.

The prevalence of SUDs related to alcohol and illegal drugs shows a systematic age-related pattern: commonly, the onset occurs during adolescence and rates peak in emerging adulthood (18-25 years; SAMHSA, 2009; Johnston et al., 2010). Adolescence is a period of specific vulnerability due to neuro-developmental immaturity (Chambers and Potenza, 2003) and to the ongoing development of inhibitory capacity (Best et al., 2009).

More than 8 million young people in the U.S. and 4.5 million in Europe live in homes with at least one parent who misuses alcohol and/or illegal drugs (Jernigan, 2001). Despite the heterogeneity of developmental outcomes (Van Voorst and Quirk, 2003; Warner et al., 2011), these children can be considered at risk for developing a SUD themselves, given the well-established intergenerational nature of the disorder (EMCDDA, 2012). Both maternal and paternal SUDs are associated with offspring's hazardous substance use and with a two-fold risk for developing SUDs; estimated prevalence rates are $53 \%$ for alcohol and 21\% for illicit drugs (Chassin et al., 1999; Alati et al., 2008; Hussong et al., 2012). Controlled studies report an earlier initiation and an accelerated transition to substance disorders for exposed offspring (Chassin et al., 1996, 1999; Hussong et al., 1998, 2008; Obot et al., 2001) and these problems have long-lasting trajectories until emerging adulthood (Baer et al., 2003; Chen and Weitzman, 2005; Melchior et al., 2011). Intriguingly from a neuro-teratological perspective, prenatal substance exposure is a direct predictor of SUDs in adolescence and young adulthood, with rates of 29 and $46 \%$ respectively (Baer et al., 2003; Alati et al., 2006; Glantz and Chambers, 2006; O'Brien and Hill, 2014), but environmental characteristics contribute to the prediction of early drug use too (Warner et al., 2011). In sum, both prenatal exposure and postnatal caregivers' drug use are unique risk factors for SUDs (Delaney-Black et al., 2011).

\section{Pathways of Parent-Child Transmission of SUDs}

A multitude of mechanisms has been recognized accounting for SUDs parent-child transmission; they include environmental, biological and genetic factors. Meta-analytic works have demonstrated the etiologic role of genes (Malone et al., 2004; Young et al., 2004; Goldman et al., 2005; Grant et al., 2013) and substance disorders in young people have been conceived as manifestation of a general and inherited liability to disinhibitory psychopathology (McGue and Iacono, 2008; Meyers and Dick, 2010).
From a biological point of view, the intrauterine exposure to maternal drug use has subtle but enduring negative effects on the central nervous system (CNS). It affects brain architecture, in terms of under-development of prefrontal structure (Bhide, 2009; Thompson et al., 2009) and functional abnormalities (Rao et al., 2007; Sheinkopf et al., 2009), ultimately causing cognitive (Warner et al., 2006; Konijnenberg and Melinder, 2011), affective, and behavioral impairments (Jutras-Aswad et al., 2009). Although the literature on the topic is scarce and results are mixed (Engeland et al., 2013), fathers' drug use prior to conception may also influence fetal developmental and birth outcomes (Cone et al., 1995; Rubes et al., 1998; Klonoff-Cohen and Lam-Kruglick, 2001; Killinger et al., 2012; Crean and Bonduriansky, 2014).

Environmental and postnatal factors contribute to the intergenerational transmission of SUDs in an independent and equal manner (Goldman et al., 2005; O'Connor and Paley, 2009; May et al., 2013), sometimes triggering and exacerbating a preexisting genetic/biological vulnerability (Schmid et al., 2009; Vaske et al., 2009). With regard to the early childrearing environment, drug-abusing mothers tend to adopt little, inadequate, and delayed prenatal care (Singer et al., 2008; Goler et al., 2012) and they show limited knowledge of their child's developmental needs as well as wrong knowledge of the pre- and postnatal effects of drug exposure (Velez et al., 2004; Strathearn and Mayes, 2010). Their parenting style is often inadequate (Baker and Carson, 1999; Hans, 2002; Eiden et al., 2011). A similar negative style of caretaking has been recognized in drug-abusing fathers, during early child development and until the teen age (Eiden et al., 1999, 2004; Eiden and Leonard, 2000; El-Sheikh and Flanagan, 2001; ElSheikh and Buckhalt, 2003; Edwards et al., 2004; Fals-Stewart et al., 2004; Crean and Bonduriansky, 2014). Since parents often deal with unemployment, social isolation and mental illness, they struggle to attend to their child's health, to guarantee financial support and basic needs (EMCDDA, 2012), to provide monitoring (Meyers and Dick, 2010), and emotional availability (Barnard and McKeganey, 2004). Children are likely to face multiple early traumatic and adverse experiences, such as household dysfunction and violence, parental incarceration, sexual, physical, and psychological abuse or neglect (Hussong et al., 2012; Anda et al., 2014; Taplin et al., 2014). A strong linear association exists between the number of adverse childhood experiences (ACEs), which have a cumulative effect, and a 2 - to 4-fold increase in the likelihood of developing early substance problems (Tonmyr et al., 2010; Taplin et al., 2014). From a broader perspective, drug-abusing families usually live in disadvantaged neighborhoods (Daniel et al., 2009), whose characteristics potentially predispose to drug use (Kliewer and Murrelle, 2007; Meyers and Dick, 2010; Stone et al., 2012).

\section{The Traumatic Nature of Being the Children of Substance-Abusing Parents}

In broad terms, both prenatal and postnatal exposure to parental alcohol and illegal drug use can be conceived as forms of early maltreatment and trauma, capable of affecting children's development. 
Prenatal exposure can be qualified as a biological condition of a potentially traumatic nature, since it is an event capable of causing death, injury or threatening the physical health, and welfare of the unborn child. Intrauterine drug exposure is a condition to which the child is subject passively and helplessly, perpetrated by the one who should be the primary caregiver and responsible for childcare; instead, drug-abusing women not only avoid adopting adequate and basic care, but they also actively persevere in harmful behaviors. Prenatal alcohol and illegal drug use is viewed as a behavior of "extreme indifference," "a conscious act of disregarding a risk ... or a failure to exercise ordinary or due care" (Cruz, 2005, p.8). Currently, several North-American States consider substance abuse during pregnancy to be child abuse or neglect, making it grounds for civil commitment and some of them have specifically criminalized it (Guttmacher Institute, 2015).

With regard to postnatal exposure, a childrearing environment characterized by the constant but unpredictable threat of adverse events can cause an overwhelming and chronic stress. Thus, living with drug-abusing parents may fall into the category of Complex Trauma, that is the experience of multiple, chronic and prolonged, developmentally adverse traumatic events, most often of an interpersonal nature and occurring in early development; complex trauma can lead to a wide range of symptoms (van der Kolk et al., 2005; Kearney et al., 2010). The applicability of the construct of complex trauma to people with SUDs has been demonstrated by a study reporting that $45 \%$ of adult addicts meet its criteria (Ford and Smith, 2008); moreover, each domain of complex trauma mediates the association between early adverse experiences and drug problems in young people (aged 16-24) (Rosenkranz et al., 2014).

Consistent with these conceptualizations of prenatal and postnatal trauma, findings in developmental traumatology indicate that they can both alter the neurophysiological growth of the nervous and endocrine systems, especially when they co-occur (Riley and McGee, 2005; Putnam, 2006; Henry et al., 2007; Lester et al., 2010; Enoch, 2011). Notably, stress response adaptation can be caused by relational components too, such as inadequate parental care and verbal abuse, even in the first years of life (Fisher and Gunnar, 2010; Enoch, 2011). These changes create a common physiological substrate that can disrupt child self-regulation and executive functions (EF; Woon and Hedges, 2008). As a result, these children are at high risk for developing psychopathology and, in turn, SUDs (Bailey and McCloskey, 2005; Putnam, 2006; Enoch, 2011).

Intrauterine drug exposure (Chapman et al., 2007) and the inadequate childrearing context related to parental drugaddiction (Lewis E. E. et al., 2007; Pears et al., 2008) mutually interact in affecting the development of regulatory systems (arousal, attentive and inhibitory control) and contribute to child neurobehavioral dysregulation during early development and adolescence (Dennis et al., 2006; Bada et al., 2007; RoseJacobs et al., 2009; Carmody et al., 2011; Fisher et al., 2011). Neurobehavioral disinhibition/dysregulation is an empiricallybased construct which refers to a broad liability dimension of risk; it encompasses a wide range of disorders that commonly co-occur (Kliewer and Murrelle, 2007; Krueger et al., 2007; Hicks et al., 2012). These disorders manifest early in childhood (Cooper et al., 2003) and follow adverse developmental trajectories, potentially leading to substance misuse in adolescence and emerging adulthood (Tarter et al., 2004; Nigg et al., 2006; McNamee et al., 2008). It has been proven that effortful control is a strong mediating factor between parental drug issues and substance use in young people (Chapman et al., 2007; Lester et al., 2012).

\section{Executive Function in Children of Drug-Addicted Parents}

Given the subtle but long-lasting effects of intrauterine drug exposure on the CNS (Mayes, 2002; Li et al., 2009), neuropsychological impairments are likely to occur in offspring of drug misusing parents. Gestational exposure to cocaine, alcohol and marijuana produces a broad array of cognitive deficits in infancy (Jacobson et al., 1996; Noland et al., 2003) and preschool age (Day et al., 1994; Griffith et al., 1994; Singer et al., 2004; Frank et al., 2005; Noland et al., 2005; Behnke et al., 2006; Lewis B. A. et al., 2007). Similarly, cognitive impairments have been reported by studies on alcohol and illegal drugs during middle childhood, mainly at the expense of EF (Kodituwakku et al., 1995; Leech et al., 1999; Rasmussen et al., 2006; Goldschmidt et al., 2008; Singer et al., 2008; Eyler et al., 2009). Functional and neuroimaging evidence has detected executive function impairments in preadolescent children prenatally exposed to cocaine, alcohol and marijuana (Olson et al., 1992; Richardson et al., 2002; Savage et al., 2005). These impaired cognitive processes seem to be associated with abnormal brain structure and activity (Mayes et al., 2005; Warner et al., 2006; Rose-Jacobs et al., 2009; Day et al., 2011).

Extensive research has also been conducted in adolescence, attesting altered frontal activation, and a broad range of difficulties in higher-order activities consequent to alcohol exposure (Olson et al., 1998; Willford et al., 2001, 2004; Mattson and Roebuck, 2002). Executive function deficits are common in drug exposed adolescent offspring (Rasmussen, 2005; RoseJacobs et al., 2011; Grant et al., 2013), but it is worth mentioning that some studies report inconsistent results and the specific effects of prenatal exposure remain unclear (Minnes et al., 2014). In some studies prenatal cocaine-exposure was not directly related to EF in (pre)adolescence (Hurt et al., 2009; Rose-Jacobs et al., 2009), as confirmed by fMRI techniques (Hurt et al., 2008). Thus, it has been proposed that the negative effects of intrauterine cocaine and alcohol exposure on EF may be subtle (Singer et al., 2008; Richardson et al., 2011), mediated by behavioral dysregulation (Fisher et al., 2011; Lester et al., 2012) and/or they might not emerge until later age (Rose-Jacobs et al., 2009).

Beyond adolescence, neuropsychological research has not extensively explored whether adult offspring are more likely to display cognitive deficits. To the best of our knowledge, only three studies have examined young adults with prenatal exposure, specifically to alcohol and marijuana; they attest deficits in cognitive measures (Kerns et al., 1997) and altered neural activity during response inhibition (Fried and Smith, 2001; Smith et al., 2006); other research has focused on adult offspring, 
documenting EF impairments (Kopera-Frye et al., 1996; Kerns et al., 1997; Connor et al., 2000).

The understanding of neurocognitive outcomes also requires the consideration of postnatal and childrearing environment characteristics; it has been well-demonstrated that being raised in economically disadvantaged backgrounds and low-income households is associated with poorer EF (Mezzacappa, 2004; Lipina et al., 2005; Noble et al., 2005, 2007; Farah et al., 2006; Moilanen et al., 2010). Poor parental nurturance and insensitive parenting are capable of influencing EF in childhood (Blair and Ursache, 2011), preadolescence (Farah et al., 2008), and adolescence (Evans and Schamberg, 2009), through stress mechanisms (Mayes, 2002; Bennett et al., 2008; Singer et al., 2008).

Finally, also youth's own drug use should be taken into account for its effect on neurocognitive functioning (Tarter et al., 1995; Tapert et al., 2002; Hanson et al., 2010; Solowij and Pesa, 2010). Studies on opioids dependence have reported deficits in neurocognition (Ersche et al., 2006; Fishbein et al., 2007; Verdejo-García et al., 2007; Brand et al., 2008). However, they address adults almost exclusively, and further evidence is needed specifically addressing youth. Empirical evidence attests that family drug history and adolescent's own drug use are different risk factors for cognitive functioning (Rose-Jacobs et al., 2011) but, at the same time, they may interact with each other (Tapert and Brown, 2000). However, to our knowledge, few studies have investigated the neuropsychological functioning in young adults who are children of drug-addicted parents and who have developed a SUD themselves.

The present study aims to investigate the role of early exposure to drugs as a traumatic event, capable of affecting the psychological status of young drug addicts. In particular, it intends to provide preliminary results on neuropsychological functioning and personality profile in young adults (aged 1824) who were diagnosed with a severe Substance Use Disorder (to the extent to be referred to residential treatment) and who were exposed to parental alcohol and illegal drug use during their prenatal and postnatal early development. In order to investigate this issue, a group of exposed drug addicts was compared to a group of drug addicts who were not exposed to drugs, and to a group of peers who did not report drug problems. On the basis of previous literature, it can be expected that exposed young drug addicts show greater neuropsychological impairments and personality disorders, given the exposure to the toxic effects of drugs and/or to the adverse childrearing environment consequent to parental drug misuse. In sum, parental drug use could be an additional factor that makes the clinical condition of young drug addicts even more severe than the one of the non-exposed counterpart.

\section{MATERIALS AND METHODS}

The present study adopted a descriptive, cross-sectional and correlational perspective for examining the neuropsychological and personality features of a group of young adults with SUDs, offspring of parents with drug problems.

\section{Participants and Procedure}

Participants with SUDs were recruited from the Therapeutic Community "Villa Renata" in Venice, Italy. The following inclusion criteria were adopted: (a) meeting DSM-IV-TR (APA, 2000) criteria for Substance Use Disorder; (b) having spent $<3$ months in the treatment facility; (c) age ranging from 18 to 24 years. 30 inpatients, aged $18-24$, constituted the clinical group of drug addicts. The assessment took place on average 1.6 months after patients' admission. At the time of recruitment, the participants had been abstinent from drugs for, on average, 3.2 months. Drug-addicted inpatients were categorized according to the criteria of having or not being exposed to parental substance misuse, as reported by records provided by the outpatient mental health services that referred the patient to the Therapeutic Community; two different groups of 15 inpatients each were obtained. The "exposed" group included young people with SUDs who had at least one biological parent with alcohol and/or illegal drug problems (cocaine, opioids, marijuana), either at the time of conception or/and during early development. The exposed participants were $66.7 \%$ male and their mean age was $20.40( \pm 2.2)$. Dichotomous variables were computed indicating the type of exposure $(0=$ absent; $1=$ present); $73.3 \%$ of the subjects were prenatally and biologically exposed, because of substance misuse by the mother during gestation $(54.5 \%)$ and/or by the father at the time of conception (63.3\%). With regard to postnatal exposure, $93.3 \%$ of the exposed group experienced an upbringing environment characterized by primary caregivers' substance related problems; $57.1 \%$ were exposed to maternal and $71.4 \%$ to paternal substance misuse during their development. The "non-exposed" inpatients were $53.3 \%$ male; the mean age was 21.13 years $( \pm 2.3)$ (see Table 1). Most of young drug addicts (both exposed and nonexposed) were characterized by low levels of education and were unemployed. The majority of subjects indicated heroin as the primary substance of abuse. However, both non-exposed and exposed inpatients were mainly poly-drug users, having used alcohol and cannabis (100\%), cocaine (93.3\%), and different synthetic drugs such as MDMA (80 and 66.7\%, respectively), and ketamine (73.3\%). In addition, the use of non-prescribed drugs was quite common, with $53.3 \%$ of non-exposed and $50 \%$ of exposed subjects using methadone procured illegally and 46.7 and $33.3 \%$ using psychiatric drugs. On average, the onset of drug-related problems occurred during adolescence at 15-16 years.

Traumatic events were computed in a categorical index, which included the experience of attachment disruptions (parental loss or abandonment, primary caretaker change, and foster care, early separation from the caregiver) and/or maltreatment or abuse (sexual, physical abuse, exploitation) in childhood and adolescence. A high percentage of exposed and nonexposed participants, 60 and $80 \%$, respectively, faced adverse events during their developmental period, often perpetuated by relatives.

The comparison group was recruited from vocational schools in an area near Venice and it included 15 young adults $(N=15)$, aged $20.3( \pm 2.1) ; 53.3 \%$ were male. The comparison subjects 
TABLE 1 | Demographics of participants.

\begin{tabular}{|c|c|c|c|}
\hline & \multicolumn{2}{|c|}{ Drug addicts (clinical group) } & \multirow[t]{2}{*}{ Non-drug } \\
\hline & Exposed & Non-exposed & \\
\hline & $\begin{array}{c}\%(N) \text { or } \\
M(S D)\end{array}$ & $\begin{array}{c}\%(N) \text { or } \\
M(S D)\end{array}$ & $\begin{array}{c}\%(N) \text { or } \\
M(S D)\end{array}$ \\
\hline Gender: female & $33.3(5)$ & $46.7(7)$ & $46.7(7)$ \\
\hline Age & $20.40( \pm 2.2)$ & $21.13( \pm 2.3)$ & $20.3( \pm 2.1)$ \\
\hline High school degree & $13.3(2)$ & $46.7(7)$ & $53.3(8)$ \\
\hline School drop-out & $80(12)$ & $73.7(7)$ & \\
\hline Years of education & $9.66( \pm 2.29)$ & $10.27( \pm 1.49)$ & $11( \pm 1.2)$ \\
\hline Unemployment & $86.7(13)$ & $53.3(8)$ & \\
\hline Poly-drug use & $80(12)$ & $80(12)$ & \\
\hline Primary drug of abuse: heroin & $66.7(10)$ & $86.7(13)$ & \\
\hline Use of synthetic drugs & $73.3(11)$ & $80(12)$ & \\
\hline Age of SUDs onset & $15.3(1.8)$ & $16(2.3)$ & \\
\hline $\begin{array}{l}\text { Age of first contact SUDs } \\
\text { services }\end{array}$ & $18.3(2.3)$ & $18.5(2.7)$ & \\
\hline SUDs-related diseases & $33.3(5)$ & $13.3(2)$ & \\
\hline Pharmacotherapy & $93.3(14)$ & $53.3(8)$ & \\
\hline Replacement therapy & $46.7(7)$ & $66.7(10)$ & \\
\hline Traumatic events & $80(11)$ & $60(9)$ & \\
\hline Early abuse/maltreatment & $40(6)$ & $40(6)$ & \\
\hline Attachment disruptions & $53.3(8)$ & $33.3(5)$ & \\
\hline Parental psychiatric problems & $13.3(2)$ & $6.7(1)$ & \\
\hline Prenatal exposure & $73.3(11)$ & & \\
\hline Intrauterine exposure & $54.5(6)$ & & \\
\hline Paternal SUDs at conception & $63.6(7)$ & & \\
\hline $\begin{array}{l}\text { Maternal and Paternal } \\
\text { prenatal exp. }\end{array}$ & $18.2(2)$ & & \\
\hline Postnatal exposure & $93.3(14)$ & & \\
\hline Maternal SUDs & $57.1(8)$ & & \\
\hline Paternal SUDs & $71.4(10)$ & & \\
\hline Maternal and paternal SUDs & $28.6(4)$ & & \\
\hline Prenatal and postnatal exposure & $66.7(10)$ & & \\
\hline
\end{tabular}

Exposed, subjects exposed to drugs early; Non-exposed, subjects not exposed to drugs early; Non-drug, subjects of the comparison group.

did not report drug use or traumatic or adverse events in their development ${ }^{1}$.

\section{Instruments}

- Brief Neuropsychological Examination-2 [Esame Neuropsicologico Breve-2] (ENB-2; Mondini et al., 2011). This is a comprehensive neuropsychological battery ideated and standardized for the Italian population. It includes 16 subtests (Digit span, Immediate and Delayed recall prose memory, Interference memory at 10 and $30 \mathrm{~s}$, a Trial making test parts A and B, Token test, Word phonemic fluency test, Abstract reasoning test, Cognitive estimation test, Test of overlapping figure, Spontaneous drawing, Copy drawing, Clock drawing, and Ideative and ideomotor praxis test).

\footnotetext{
${ }^{1}$ Subjects of the study were part of a larger research protocol approved by the Ethic Commette of the University of Padova
}

The ENB-2 allows to investigate several cognitive domains: attention, executive functioning, perception, praxis abilities, and comprehension. The battery provides both an assessment of the single cognitive tasks and a total score (Global cognitive index) indicating the overall cognitive profile. Age (1520, 21-30 years) and education (lower than 9 years and higher) are the two criteria used to identify subgroups of individuals and their respective normative scores. The 5th percentile was used to determine cut-off scores for each subgroups; according to the cut-off score, the performance is classified in three categories: below average (impaired), at the limit, and average (normative). The battery shows good psychometric characteristics, revealing good differential validity in discriminating normative and clinical groups and sufficient test-retest reliability (range from 0.57 to 0.97 ) (Mondini et al., 2003, 2011).

- The Shedler-Westen Assessment Procedure (SWAP-200; Westen and Shedler, 1999a,b) is a set of 200 descriptive statements (items) regarding adult personality aspects. It is based on the Q-Sort method, with fixed score distribution, and it requires the clinician to sort the items into eight categories based on their applicability to the patient, from 7 (highly descriptive) to 0 (not descriptive). The major advantage of the present assessment is that it relies on an external observer's judgment instead of self-reporting, which is subject to a number of biases. The SWAP-200 assessment provides: (a) a personality diagnosis expressed as the matching of the patient's description with 10 prototypical descriptions of DSM-IV personality disorders (standardized score named PD-T); according to DSM, the 10 personality disorders are grouped into three clusters $(A, B, C)$; (b) a personality diagnosis based on the matching of the patient with 11 Q-factors of personality derived empirically (standardized scores named Q-T); (c) a dimensional profile of healthy and adaptive functioning. The presence of one or more personality disorders is determined when the patient's PD-T and/or Q-T are $\geq 60$ and the adaptive functioning scale is $\leq 60$; if the score ranges from 55 to 60 , then subclinical traits of that personality disorder or style are present. In sum, the SWAP-200 provides both categorical and dimensional diagnoses. The reliability of SWAP-200 personality descriptions range from 0.75 to 0.89 (Shedler and Westen, 1998; Westen and Muderrisoglu, 2003; Marin-Avellan et al., 2005) and scores correlate with several external criterion measures (e.g., Westen and Shedler, 1999a; Westen and Muderrisoglu, 2003; Westen and Weinberger, 2004). The study by Blagov et al. (2012), after reviewing empirical evidence on the SWAP-200, attests its validity and reports new test-retest reliability data (median coefficient $>$ 0.85). To our knowledge, an Italian translation of the SWAP200 is currently available (Lingiardi et al., 2006; Shedler et al., 2014). Given the need for a clinician's judgment to complete the SWAP-200, this assessment was not administered to the comparison group.

- The Symptom Checklist-90-Revised (SCL-90-R; Derogatis, 1994). It is a self-report measure assessing 90 clinical symptoms on a 5-point Likert scale, ranging from 0 (not at all) to 4 (extremely). The symptoms are factored into nine 
psychiatric dimensions (depression, anxiety, somatization, obsessive-compulsive behavior, interpersonal sensitivity, hostility, phobic anxiety, psychoticism, and paranoid ideation), plus altered appetite and disturbed sleep. The instrument provides three global scores: the Global Stress Index (GSI) indicating the general psychological distress of the individual; the Positive Symptom Total (PST), revealing the number of symptoms the respondent has endorsed to any degree; the Positive Symptom Distress Index (PSDI), a measure of distress intensity. The psychometric properties of the original version of the checklist show acceptable levels of internal consistency (ranging from 0.77 to 0.90), test-retest reliability (ranging from 0.68 to 0.90 ) and convergent and discriminant validity (Derogatis, 2011). However, despite the extensive and widespread application of the instrument, some studies have questioned its factorial invariance across different samples (Cyr et al., 1985; Prunas et al., 2012). The Italian translation and adaptation of the SCL-90-R (Sarno et al., 2011) show adequate results for Principal Component Analysis (a single factor explains $65.22 \%$ of the variance) and internal consistency with Cronbach's alpha (from 0.68 to 0.87 for the nine dimensions and $=0.97$ for the GSI score).

\section{RESULTS}

Data were analyzed using the IBM Statistical Package for the Social Sciences (SPSS) 23.0. The qualitative analysis was carried out using descriptive statistics (frequencies, mean scores, and percentages), while for the quantitative analysis, due to the small number of subjects, non-parametric tests were applied (the Mann-Whitney U test, Pearson's Chi-Square test, and Spearman's Rho correlation).

\section{Descriptive Analysis}

Results on the psychological distress assessed by the self-report SCL-90-R displayed that more than a half of both exposed and non-exposed young inpatients showed clinically significant scores on the global symptomatological profile, with GSI scores above the clinical cut-off for 53.3 and $66.7 \%$ of individuals respectively, as shown in Table 2. Similarly, the evaluation of symptoms' number (PST) and intensity (PSDI) showed high values for a considerable number of subjects in both groups, especially the non-exposed one. The majority of drug addicts biologically or environmentally exposed to parental SUDs fall in the clinical range for anxiety and depression, while most of the non-exposed individuals revealed high levels of depression, hostility, and psychoticism.

The SWAP-200 procedure indicated that Personality Disorders (PDs) were frequent among young drug addicts of both groups. With respect to DSM classification, $66.7 \%$ of exposed and $46.7 \%$ of non-exposed drug addicts showed at least one $\mathrm{PD}$ diagnosis. The primary diagnosis referred more frequently to cluster B (for $46.7 \%$ of the exposed subjects and $26.7 \%$ of the non-exposed ones), while in both groups $13.3 \%$ of the individuals received a cluster A primary diagnosis and $6.7 \%$ a cluster $\mathrm{C}$ primary diagnosis. Histrionic Personality
Disorder was the most common primary diagnosis, with $20 \%$ of the exposed patients and $13.3 \%$ of the non-exposed young addicts. Considering the presence of both traits and disorders, the exposed group showed high rates of Borderline Personality features, while the non-exposed group showed high rates of Dependent and Schizotypal characteristics. In relation to the Q-factor categorization, a PD diagnosis was detected in $80 \%$ of the exposed subjects and in $60 \%$ of their counterpart. The primary diagnosis were Dependent personality style for the former (33.3\%) and Histrionic (13.3\%) for the latter. Depressive, Dysregulated and Antisocial components were frequent in the exposed group, while non-exposed drug addicts showed high rates of Antisocial and Hostile functioning. The adaptive functioning resulted inadequate for $73.3 \%$ of individuals with parental SUDs and for $93.3 \%$ of inpatients without past drug exposure (Table 3 ).

With regard to neuropsychological functioning, the results of the ENB-2 showed that $80 \%$ of inpatients with parental drug exposure had an impaired global cognitive profile, considering both those whose Global cognitive index reached the limits of the normative performance and those who had fully impaired neuropsychological functioning. This rate seemed to exceed the one of the non-exposed drug addicts. Observing the performance of the single tests of the ENB-2 battery, deficits occurred primarily in the domain of executive function, with three subtests displaying a high percentage of impairments, namely: TmtB (73.3\%) (a test of attention and task switching, providing information about visual search speed, mental flexibility, and EF); Cognitive estimation test (assessing the capacity of answering a question for which relevant knowledge, but not the specific answer, is available) and Clock drawing test (which taps into a wide range of cognitive abilities including $\mathrm{EF}$ ) with rates of $46.6 \%$ each. Other impairments occurred frequently in the memory domain, specifically the Immediate Recall test and the Interference test at $30 \mathrm{~s}$. The non-exposed individuals showed a similar pattern of executive and memory problems, but with lower rates of altered performance. Notably, $66.7 \%$ of the non-exposed young addicts demonstrated no or one deficit in the executive domain, while those in patients who were exposed to parental SUDs during development had an impaired performance in at least two tests (maximum five) in $73.3 \%$ of cases (see Table 4).

\section{Comparing the Two Clinical Groups and the Comparison Group}

First, concerning the important socio-demographical variables capable of influencing the performance at the neuropsychological battery (cfr. Mondini et al., 2011), the three groups were compared for age and years of education. The Kruskal-Wallis test did not report significant differences (age $X^{2}=1.643, p=0.440$, ns), (education $X^{2}=4.788, p=0.091$, ns). Also, the use of the Mann-Whitney test confirmed that the comparison group was similar in age both to the exposed $(z=-0.085, p=0.935$, ns) and to the non-exposed group $(z=-1.268, p=0.217$, $n s)$. With regard to years of education, there was no significant difference according to the Bonferroni correction between the 
TABLE 2 | Symptomatological profile at SCL-90-R.

\begin{tabular}{|c|c|c|c|c|c|c|c|c|c|c|c|c|}
\hline \multirow[t]{3}{*}{ Scales } & \multicolumn{8}{|c|}{ Drug addicts (clinical group) } & \multicolumn{4}{|c|}{ Non-drug } \\
\hline & \multicolumn{4}{|c|}{ Exposed } & \multicolumn{4}{|c|}{ Non-exposed } & \multirow[b]{2}{*}{$\min$} & \multirow[b]{2}{*}{$\max$} & \multirow[b]{2}{*}{$M(S D)$} & \multirow[b]{2}{*}{ Clinical \% $(N)$} \\
\hline & $\min$ & $\max$ & $M(S D)$ & Clinical \% (N) & $\min$ & $\max$ & $M(S D)$ & Clinical \% $(N)$ & & & & \\
\hline Somatization & 39 & 76 & $54.20(12.04)$ & $40.0(6)$ & 39 & 76 & $56.40(14.62)$ & $53.3(8)$ & 37 & 72 & $50.07(10.71)$ & $26.7(4)$ \\
\hline Obsessionality & 37 & 72 & $54.53(11.82)$ & $46.7(7)$ & 37 & 75 & $54.87(12.58)$ & $53.3(8)$ & 37 & 61 & $47.20(8.15)$ & $20.0(3)$ \\
\hline Inter. sensitivity & 40 & 76 & $54.93(13.59)$ & $40.0(6)$ & 38 & 74 & $56.20(11.95)$ & $53.3(8)$ & 38 & 60 & $46.27(8.22)$ & $20.0(3)$ \\
\hline Depression & 43 & 76 & $58.33(11.88)$ & $60.0(9)$ & 44 & 76 & $62.80(11.51)$ & $66.7(10)$ & 35 & 63 & 48.07 (7.96) & 26.7 (4) \\
\hline Anxiety & 40 & 76 & $59.20(12.68)$ & $53.3(8)$ & 43 & 76 & $59.13(13.58)$ & $53.3(8)$ & 39 & 64 & $49.40(8.71)$ & $33.3(5)$ \\
\hline Hostility & 41 & 76 & $58.13(12.14)$ & 46.7 (7) & 39 & 76 & 60.67 (13.47) & $66.7(10)$ & 38 & 60 & $47.27(6.74)$ & $20.0(3)$ \\
\hline Phobic anxiety & 43 & 76 & $55.67(13.11)$ & $40.0(6)$ & 43 & 76 & $49.93(10.10)$ & $20.0(3)$ & 42 & 76 & $48.40(9.61)$ & 20.0 (3) \\
\hline Paranoid ideat. & 39 & 76 & $55.60(15.22)$ & $46.7(7)$ & 36 & 76 & $59.60(13.37)$ & $60.0(9)$ & 36 & 63 & 51.27 (8.79) & 46.7 (7) \\
\hline Psychoticism & 42 & 76 & 57.00 (13.33) & $40.0(6)$ & 42 & 76 & $60.93(11.42)$ & $66.7(10)$ & 40 & 56 & $47.47(5.12)$ & $13.3(2)$ \\
\hline GSI & 39 & 76 & 57.87 (12.99) & $53.3(8)$ & 41 & 76 & 60.33 (12.60) & $66.7(10)$ & 39 & 62 & $48.60(7.85)$ & $26.7(4)$ \\
\hline PST & 35 & 73 & $55.20(11.30)$ & 53.3 (8) & 37 & 75 & $55.87(11.91)$ & $60.0(9)$ & 33 & 65 & 48.33(10.49) & $33.3(5)$ \\
\hline PSDI & 42 & 76 & $58.40(14.01)$ & $53.3(8)$ & 48 & 76 & $63.73(9.64)$ & $80.0(12)$ & 30 & 63 & 49.67 (8.33) & 26.7 (4) \\
\hline
\end{tabular}

Clinical, percentages of individuals who obtained scores above the normative cut-off; GSI, Global Severity Index; PST, Positive Symptom Total; PSDI, Positive Symptom Distress Index.

comparison group and the exposed individuals $(p=0.05 / 2=$ $0.025)(z=2.113, p=0.041)$ and with the non-exposed subjects $(z=-1.390 ; p=0.187, \mathrm{~ns})$.

Second, the symptomatological features of the three groups were analyzed in order to ascertain if the comparison group did not display any significant clinical status, as opposed to the two groups with SUDs. The Kruskal-Wallis test by ranks revealed a significant difference among the three independent samples for the global indexes GSI $\left(X^{2}=7.247, p=0.027\right)$ and PSDI $\left(X^{2}=9.334, p=0.009\right)$, and for 5 psychiatric dimensions: interpersonal sensitivity $\left(X^{2}=6.416, p=0.040\right)$, depression $\left(X^{2}\right.$ $=11.694, p=0.003)$, anxiety $\left(X^{2}=6.006, p=0.050\right)$, hostility $\left(X^{2}=19.377, p=0.009\right)$ and psychoticism $\left(X^{2}=10.709\right.$, $p=0.005$ ) (Figure 1); results for depression and psychoticism remained significant when the Bonferroni correction was used. While the chi-square test did not report any significant results, the Mann-Whitney U test reported that the comparison group differed from the exposed group for the Global Stress Index, GSI $(z=-1.96, p=0.049)$ and for the symptomatic dimensions of depression $(z=-2.35, p=0.019)$, anxiety $(z=-2.12, p=$ 0.033 ), hostility $(z=-2.56, p=0.010)$ (significant also for Bonferroni correction) and psychoticism $(z=-1.99, p=0.049)$. It also significantly differed from the non-exposed drug addicts group, for the GSI $(z=-2.55, p=0.010)$, PSDI $(z=-3.28$, $p=0.001)$ and 5 scales, interpersonal sensitivity $(z=-2.41, p=$ $0.015)$, depression $(z=-3.14, p=0.001)$, anxiety $(z=-2.10$, $p=0.037)$, hostility $(z=-2.64, p=0.008)$ and psychoticism $(z=-3.31, p=0.001)$. The use of Bonferroni test revealed significant results for PSDI, depression and psychoticism.

Finally, to investigate the neuropsychological functioning and the potential presence of specific deficits among drug-addicted offspring of drug misusing parents, we first used the KruskalWallis test to compare the $\mathrm{z}$-scores: the 3 groups showed a different global cognitive profile $\left(\mathrm{X}^{2}=13.570, p=0.001\right)$. Moreover, a significant difference emerged for two measures of attention and executive function, the Trial Making Test$\mathrm{A}\left(\mathrm{X}^{2}=13.178, p=0.001\right)$ and $-\mathrm{B}\left(\mathrm{X}^{2}=14.674\right.$, $p=0.001)$, also according to Bonferroni correction $(p=$ $0.05 / 3=0.017$ ) (Figure 2). The Mann-Whitney's U test reported that the exposed group showed a poorer performance in the Tmt$\mathrm{A}$ and Tmt-B tests $(z=-3.218, p=0.001)(z=-3.780$, $p=0.000)$ and a lower global cognitive profile $(z=-2.826$, $p=0.004)$ compared to the non-clinical group. The Pearson's Chi-square test confirmed the previous results concerning the presence/absence of deficits in the 3 abovementioned measures: Global cognitive index $\left(\mathrm{X}^{2}=6.000, p=0.042\right)$, Tmt- $\mathrm{A}\left(\mathrm{X}^{2}=\right.$ 17.368, $p=0.000)$ and Tmt-B $\left(\mathrm{X}^{2}=10.800, p=0.003\right)$. All these results remained significant according to the Bonferroni correction $(p=0.05 / 3=0.017)$, with the only exception of Global cognitive index. With regard to the comparison between the non-clinical group and the non-exposed group, only the Tmt$B$ test showed significant results, for both the Mann-Whitney test $(z=-3.332, p=0.041)$ and the Pearson's Chi-square test $\left(\mathrm{X}^{2}=\right.$ $6.000, p=0.042)$.

\section{Comparing Exposed and Non-exposed Groups}

The two clinical groups were first compared in relation to the symptomatological profile at the SCL-90-R; neither the MannWhitney nor the Pearson's Chi-square tests reported significant differences between young drug addicts prenatally and/or postnatally exposed to parental SUDs and non-exposed drugaddicted inpatients. Similarly, a comparison of the personality assessment with the SWAP-200 procedure did not reveal specific characteristics in one of the two groups, with comparable levels of personality adaptive functioning and personality disorders and traits.

Instead, significant differences emerged in the neuropsychological functioning of the two groups of inpatients; 
TABLE 3 | Personality traits and disorder scores at the SWAP-200 for the clinical groups.

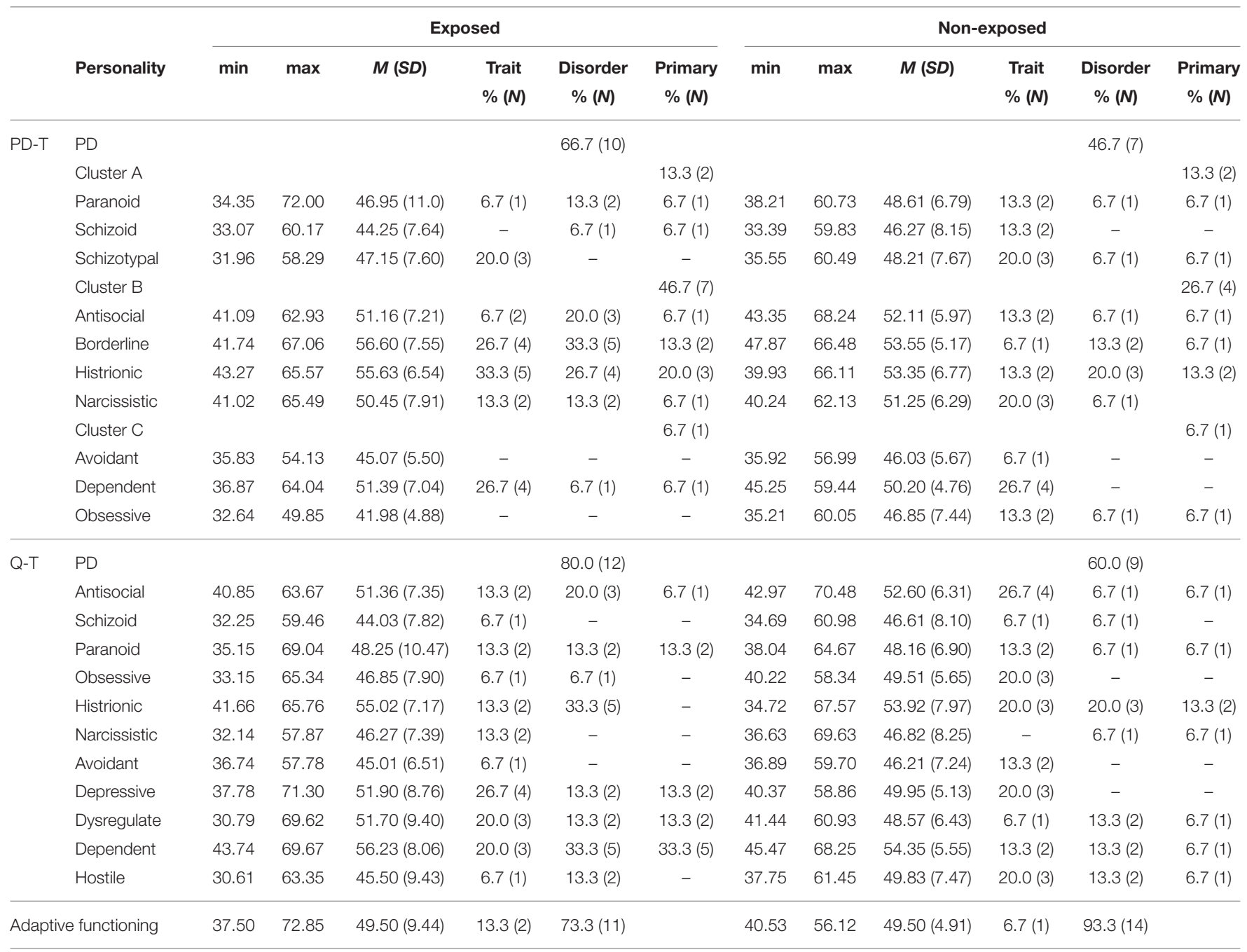

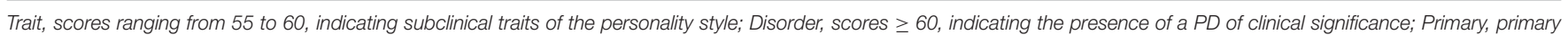
diagnosis, that is the personality disorder with highest score; PD, presence of a Personality Disorder diagnosis.

individuals exposed to parental SUDs at the time of conception, intrauterine life and/or developmental age showed a poorer global cognitive profile for the Mann-Whitney test $(z=-3.324$, $p=0.002)$ and for the Chi-square test $\left(\mathrm{X}^{2}=10.800, p=0.003\right)$. Concerning the single tasks of the battery, the exposed group demonstrated more problems in the Tmt-A test $(z=-3.032$, $p=0.002$ ). Results remained significant when the Bonferroni correction was used $(p=0.05 / 2=0.025)$.

A post hoc power analysis was performed for the Chi square and Mann-Whitney tests; the post hoc power of the study $(1-\beta)$ were 0.37 and 0.25 respectively, indicating that the effect is small and the sample size is small as well.

\section{Correlational Analysis}

Spearman's Rho was applied to test for any associations between the different measures adopted in the study. The main interest focused on potential associations between demographic measures that were relevant for the purposes of the research (the traumatic nature of being exposed to parental drug use) and psychological characteristics, in particular neuropsychological functioning. Results reported that the Global cognitive index was negatively correlated with having a parent with SUDs ( $r$ $\left.=-0.617^{* *}, p=0.000\right)$, while the number of impaired EF was positively associated with it $\left(r=0.459^{*}, p=0.011\right)$. Importantly, the number of past traumatic experience (namely attachment disruptions and/or abuse) correlated positively with the number of executive impairments $\left(r=0.381^{*}, p=\right.$ 0.038). As expected, the level of education is inversely associated with executive performance $\left(r=-0.392^{*}, p=0.032\right)$ and positively with the Global cognitive index $\left(r=0.440^{*}, p=\right.$ 0.015). No significant associations emerged between these two cognitive composite measures and personality or symptom assessments.

\section{DISCUSSION}

The present investigation reports preliminary results which indicate that young adults (aged 18-24) with SUDs showed a 
TABLE 4 | Percentages of patients with altered neuropsychological functioning.

\begin{tabular}{|c|c|c|c|}
\hline \multirow[t]{3}{*}{ Cognitive ability } & \multicolumn{2}{|c|}{ Drug addicts (clinical group) } & \multirow{3}{*}{$\begin{array}{c}\text { Non-drug } \\
\%(N)\end{array}$} \\
\hline & Exposed & Non-exposed & \\
\hline & $\%(N)$ & $\%(N)$ & \\
\hline \multicolumn{4}{|l|}{ ATTENTION } \\
\hline Tmt-A & $33.3(5)$ & $6.7(1)$ & - \\
\hline Tmt-B & $73.3(11)$ & $33.3(5)$ & - \\
\hline \multicolumn{4}{|l|}{ MEMORY } \\
\hline Digit span & $6.7(1)$ & $6.7(1)$ & $6.7(1)$ \\
\hline Immediate recall & $46.7(7)$ & $33.3(5)$ & $40.0(6)$ \\
\hline Delayed recall & $33.3(5)$ & $20.0(3)$ & $33.3(5)$ \\
\hline Interference 10s & $33.3(5)$ & $20.0(3)$ & $13.3(2)$ \\
\hline Interference 30s & $46.7(7)$ & $20.0(3)$ & $13.3(2)$ \\
\hline \multicolumn{4}{|c|}{ EXECUTIVE FUNCTIONS } \\
\hline Tmt-B & $73.3(11)$ & $33.3(5)$ & - \\
\hline Cognitive estimation & $46.7(7)$ & $33.3(5)$ & - \\
\hline Abstract reasoning & $33.3(5)$ & $6.7(1)$ & $20.0(3)$ \\
\hline Phonemic fluency & $26.7(4)$ & $13.3(2)$ & $33.3(5)$ \\
\hline Clock drawing & $46.7(7)$ & $26.7(4)$ & $26.7(4)$ \\
\hline Overlapping figures & $13.3(2)$ & $6.7(1)$ & $6.7(1)$ \\
\hline \multicolumn{4}{|l|}{ PERCEPTION } \\
\hline Spontaneous drawing & - & $6.7(1)$ & $6.7(1)$ \\
\hline Copy drawing & $33.3(5)$ & $26.7(4)$ & $33.3(5)$ \\
\hline \multicolumn{4}{|l|}{ Praxis Ability } \\
\hline Ideomotory praxis & $6.7(1)$ & - & $6.7(1)$ \\
\hline \multicolumn{4}{|l|}{ COMPREHENSION } \\
\hline Token test & $13.3(2)$ & - & - \\
\hline Global Index & $80.0(12)$ & $20.0(3)$ & $20.0(3)$ \\
\hline \multicolumn{4}{|l|}{ Number of impaired EF } \\
\hline $0-1$ & $26.7(4)$ & $66.7(10)$ & $40.0(6)$ \\
\hline $2-5$ & $73.3(11)$ & $33.3(5)$ & $60.0(9)$ \\
\hline
\end{tabular}

Global Index, index of the overall cognitive profile; Number of impaired EF, number of tasks assessing executive functions showing an impaired performance.

severe clinical condition; in particular, those who were exposed to parental alcohol and/or illicit drug use during their prenatal and/or postnatal development showed specific dysfunctional traits, compared with two groups of peers matched for age and level of education.

With regard to the preliminary analysis, while the symptomatological status could differentiate young people with SUDs from non-dependent young adults to some degree, the two clinical groups of inpatients had a high psychological distress at the moment of the assessment. On the basis of equal symptomatic distress, the examination of the personality profile with SWAP-200 indicated no significant characteristics in young drug addicts who were subject to drug-exposure compared to those who were not, suggesting that parents' drug issues may not have consequences for the development of specific personality traits or disorders. Research on personality of offspring of drugdependent parents is mostly limited to personality characteristics and to children who have not developed a SUD themselves
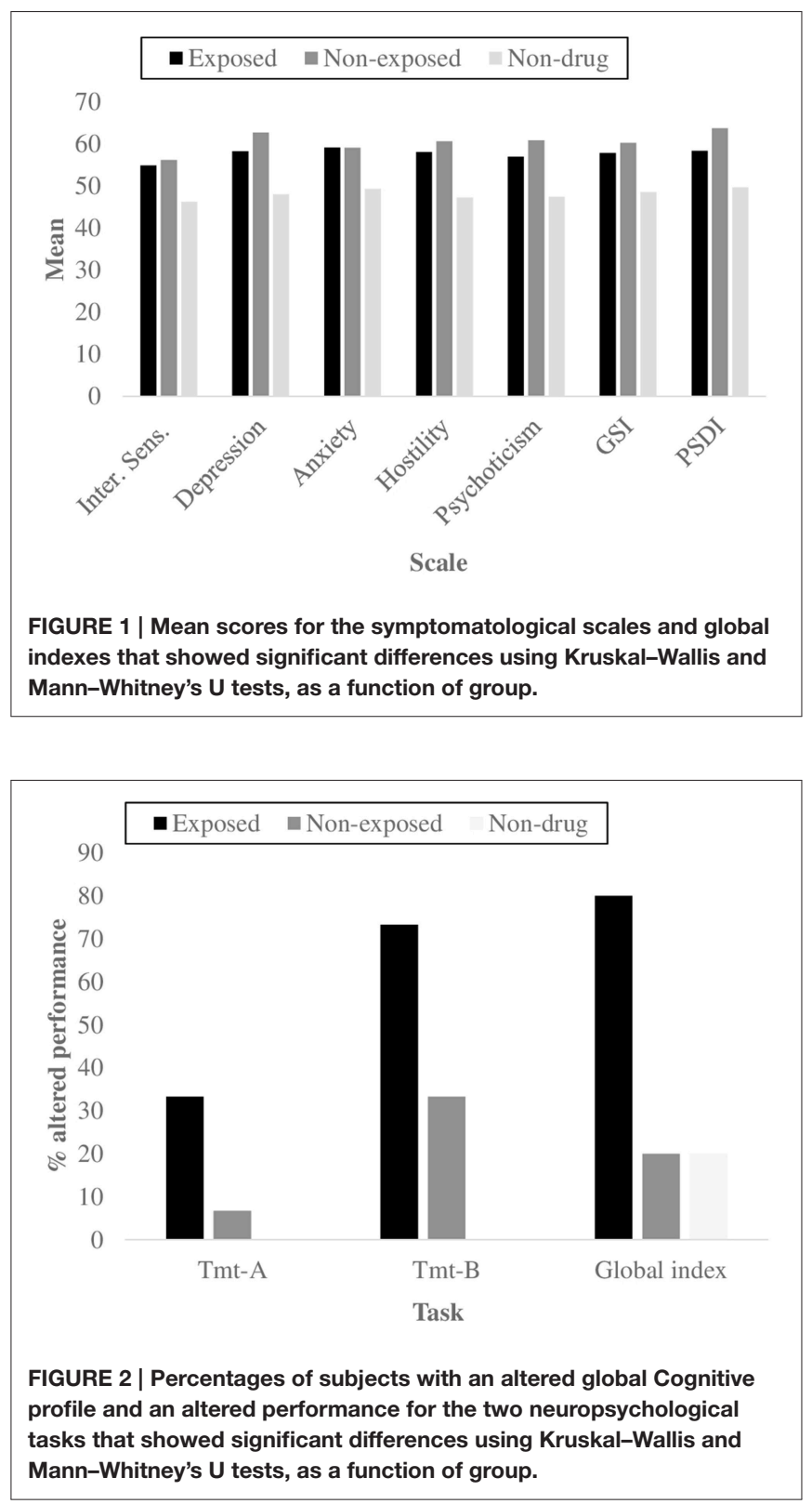

(Barr et al., 2006; Elkins et al., 2006; Morgan et al., 2010; Hinrichs et al., 2011), providing scarce data to compare with the present results. However, the lack of dissimilarity between the two groups suggests that personality disorders constitute the dysfunctional outcome of developmental trajectories that are not exclusively associated with parents' addiction problems. Rather, personality disorders (PDs) can be ascribed to a wide range of factors, including environmental variables which date back to childhood and adolescence, and which encompass maladaptive parenting, aversive interactive patterns with the primary caregivers, early adverse experiences and household dysfunction (Gibb et al., 2001; Afifi et al., 2011). The investigation of the role played by these factors goes beyond the aims of the present study, but further research should clarify this issue in 
the specific case of second-generation addicts. The high rates of personality disorders in our sample are in line with other (but still limited) studies specifically targeting young drug addicts, which estimate a prevalence of 46-61\% (Kokkevi et al., 1998; Langås et al., 2012). On the one hand, our findings are consistent with research attesting a pervasiveness of Cluster B disorders among individuals with SUDs (Kokkevi et al., 1998; Mackesy-Amiti et al., 2012); this co-occurrence is explained by impulsivity, considered a common etiological process (Bornovalova et al., 2005; Krueger et al., 2007), On the other hand, it is worth mentioning that about $33 \%$ of the individuals in our group met the criteria for Dependent Personality as primary diagnosis, resembling other investigations which report Cluster C disorders in young substance users (Langås et al., 2012). The high percentage of Cluster C disorders, specifically Dependent PDs, might be explained by the application of a quite innovative assessment procedure, the SWAP-200. First, it relies on an external observer's judgment instead of self-reporting; secondly, it asks the clinician to base his/her judgments not only on the observation of manifest behaviors, but on some inference about internal psychological processes as well. Thus, the SWAP-200 assessment might have drawn attention to Dependent personality traits, otherwise overlooked.

Parental drug issues seemed to play a different role concerning the neuropsychological functioning of young-adult offspring with SUDs; those exposed to childrearing environments affected by addiction (prenatally and/or postnatally) showed more cognitive impairments, especially at the expense of EF, in terms of attention shifting and mental flexibility. From a qualitative point of view, the executive domains of cognitive estimation, planning and memory also displayed an inadequate performance. Interestingly, the data are similar to those reported by Warner et al. (2006). Executive function deficits are particularly critical, given their role for individual adjustment and emotional competences (McClelland et al., 2007; Blair and Ursache, 2011). The presence of reduced higher-order cognitive efficiency in the group of drug-addicted offspring can be explained referring to the contribution of multiple interacting factors. First, a vast literature attests that prenatal drug exposure leads to subtle but enduring consequences for the prefrontal cortex and can cause cognitive impairments in childhood, adolescence (e.g., Warner et al., 2006; Rose-Jacobs et al., 2011) and young adulthood, even if research is more restricted in this developmental stage (Kerns et al., 1997; Fried and Smith, 2001; Smith et al., 2006). Considering these established long-lasting and harmful effects, drug taking during pregnancy can be considered a form of maltreatment and trauma, which occur extremely early and function as an early matrix for later maladaptive developmental trajectories. Second, being raised in an adverse and deprived environment (with parents scarcely involved in promoting their child's education and providing environmental stimulation) and having experienced early traumatic events (often of an interpersonal nature) are factors capable of compromising optimal cognitive development (Mayes, 2002; El-Sheikh and Buckhalt, 2003; Bennett et al., 2008; Singer et al., 2008). Eventually, if previous impairments of the executive and control abilities can predispose to substance use (Giancola and Tarter,
1999), it is also proven that drug misuse during the highly sensitive adolescent years (Chambers and Potenza, 2003) has a detrimental effect on cognitive abilities (Tapert et al., 2002; Hanson et al., 2010; Solowij and Pesa, 2010).

Although the present study has some strengths (addressing a very specific clinical group and not relying on self-reporting for personality assessment), the current results should be interpreted relative to some limitations, which underlie the preliminary nature of the research.

The major limitation regards the small sample size; as a matter of fact, power analyses revealed that the effect is small and the sample size is small as well; future studies will necessitate a sample size that exceeds the currently available resources.

Second, the cross-sectional nature of the study does not allow conclusions on the causality link between the examined factors; in order to clarify this association, other research designs could provide more accurate information; for example, a longitudinal approach would be extremely useful to better understand the developmental pathways in offspring at risk because of parental mental health problems. However, this type of studies shows several challenges in feasibility and sometimes might be not possible at all. Alternatively, innovative statistical and mathematical methods may constitute a valuable alternative approach for future research, as suggested by Maurage et al. (2013).

Other limitations include the use of dichotomies for the consideration of parental substance misuse and the lack of distinction among different drugs used by parents and young addicts (alcohol, cocaine, heroin, marijuana); moreover, further research should adopt an accurate control of important variables such as gender, socio-economic status, type of traumatic experiences. It has been recognized that other relevant factors are capable of compromising optimal cognitive functioning (Mezzacappa, 2004; Bennett et al., 2008; Dikmen et al., 2009; Evans and Schamberg, 2009; Hackman and Farah, 2009). Thus, future studies might investigate the role of childrearing environment characteristics on the neuropsychological functioning, since the present research did not examine these aspects.

In conclusion, the preliminary results of this study have pointed out that parental drug use could be an additional factor that makes the clinical condition of young drug addicts particularly severe (especially in terms of neuropsychological impairments), contributing to the currently limited knowledge on young-adult children of drug-dependent parents, with SUDs themselves. Replication of the present data is necessary in order to increase confidence in results and to better guide clinical implications that the study has preliminarily indicated. In particular, a strong need would emerge for multi-focused prevention and intervention programs for young adults with SUDs in general, and specifically for second-generation addicts. First, assessment and treatment programs are required to target drug-addicted mothers and their at-risk children as early as the prenatal and early postnatal periods (Stocco et al., 2012; De Palo et al., 2014). With regard to EF, early prevention and educational protocols should sustain cognitive development of children of drug-addicted parents (Minnes et al., 2014), in 
order to buffer their vulnerability and prevent future detrimental outcomes. Recent studies indicate that specific trainings, such as mindfulness, can ameliorate executive function even in adulthood (Posner et al., 2014). Concerning young adults with established SUDs, neurocognitive deficits are likely to interfere with treatment and recovery (Aharonovich et al., 2006; Grant et al., 2013); as a consequence, the introduction of protocols targeting cognitive functions is highly recommended. Moreover, programs for drug-addicted offspring of parents with SUDs should be augmented with an integrative approach that combines trauma-focused work and that adopts a developmental perspective, bridging the gap between childhood and outcomes in early adulthood. Despite a growing awareness of the need

\section{REFERENCES}

Afifi, T. O., Mather, A., Boman, J., Fleisher, W., Enns, M. W., MacMillan, H., et al. (2011). Childhood adversity and personality disorders: results from a nationally representative population-based study. J. Psychiatr. Res. 45, 814-822. doi: 10.1016/j.jpsychires.2010.11.008

Aharonovich, E., Hasin, D. S., Brooks, A. C., Liu, X., Bisaga, A., and Nunes, E. V. (2006). Cognitive deficits predict low treatment retention in cocaine dependent patients. Drug Alcohol Depend. 81, 313-322. doi: 10.1016/j.drugalcdep.2005.08.003

Alati, R., Al Mamun, A., Williams, G. M., O'Callaghan, M., Najman, J. M., and Bor, W. (2006). In utero alcohol exposure and prediction of alcohol disorders in early adulthood: a birth cohort study. Arch. Gen. Psychiatry 63, 1009-1016. doi: 10.1001/archpsyc.63.9.1009

Alati, R., Clavarino, A., Najman, J. M., O'Callaghan, M., Bor, W., Al Mamun, A., et al. (2008). The developmental origin of adolescent alcohol use: findings from the Mater University Study of Pregnancy and its outcomes. Drug Alcohol Depend. 98, 136-143. doi: 10.1016/j.drugalcdep.2008.05.011

American Psychiatric Association (APA) (2000). Diagnostic and Statistical Manual of Mental Disorders, 4th Edn, Text Rev. Washington, DC: American Psychiatric Association.

American Psychiatric Association (APA) (2013). Diagnostic and Statistical Manual of Mental Disorders, 5th Edn. Washington, DC: American Psychiatric Association.

Anda, R. F., Whitfield, C. L., Felitti, V. J., Chapman, D., Edwards, V. J., Dube, S. R., et al. (2014). Adverse childhood experiences, alcoholic parents, and later risk of alcoholism and depression. Psychiatr. Serv. 53, 1001-1009. doi: 10.1176/appi.ps.53.8.1001

Bada, H. S., Das, A., Bauer, C. R., Shankaran, S., Lester, B., LaGasse, L., et al. (2007). Impact of prenatal cocaine exposure on child behavior problems through school age. Pediatrics 119, 348-359. doi: 10.1542/peds.2006-1404

Baer, J. S., Sampson, P. D., Barr, H. M., Connor, P. D., and Streissguth, A. P. (2003). A 21-year longitudinal analysis of the effects of prenatal alcohol exposure on young adult drinking. Arch. Gen. Psychiatry 60, 377-385. doi: 10.1001/archpsyc.60.4.377

Bailey, J. A., and McCloskey, L. A. (2005). Pathways to adolescent substance use among sexually abused girls. J. Abnorm. Child Psychol. 33, 39-53. doi: 10.1007/s10802-005-0933-0

Baker, P. L., and Carson, A. (1999). I take care of my kids. Mothering practices of substance-abusing women. Gend. Soc. 13, 347-363. doi: $10.1177 / 089124399013003005$

Barnard, M., and McKeganey, N. (2004). The impact of parental problem drug use on children: what is the problem and what can be done to help? Addiction 99, 552-559. doi: 10.1111/j.1360-0443.2003.00664.x

Barr, H. M., Bookstein, F. L., O'Malley, K. D., Connor, P. D., Huggins, J. E., and Streissguth, A. P. (2006). Binge drinking during pregnancy as a predictor of psychiatric disorders on the Structured Clinical Interview for DSM-IV in young adult offspring. Am. J. Psychiatry 163, 1061-1065. doi: 10.1176/ajp.2006.163.6.1061

Behnke, M., Eyler, F. D., Warner, T. D., Garvan, C. W., Hou, W., and Wobie, K. (2006). Outcome from a prospective, longitudinal study of prenatal cocaine for trauma-informed substance abuse treatment (Brown et al., 2008; Taplin et al., 2014), nowadays there are few intervention programs addressing complex trauma experiences that preexist/co-exist with SUDs in young adulthood (Rosenkranz et al., 2014), requiring further development.

\section{AUTHOR CONTRIBUTIONS}

MP, AS, DM, MS and PC have given a substantial contribution to the ideation and implementation of the work, taking part to data acquisition, analysis, and interpretation, drafting and revising the manuscript, and reaching an agreement on the final version of the work.

use: preschool development at 3 years of age. J. Pediatr. Psychol. 31, 41-49. doi: 10.1093/jpepsy/jsj027

Bennett, D. S., Bendersky, M., and Lewis, M. (2008). Children's cognitive ability from 4 to 9 years old as a function of prenatal cocaine exposure, environmental risk, and maternal verbal intelligence. Dev. Psychol. 44, 919-928. doi: 10.1037/0012-1649.44.4.919

Best, J. R., Miller, P. H., and Jones, L. L. (2009). Executive functions after age 5 : changes and correlates. Dev. Rev. 29, 180-200. doi: 10.1016/j.dr.2009.05.002

Bhide, P. G. (2009). Dopamine, cocaine and the development of cerebral cortical cytoarchitecture: a review of current concepts. Semin. Cell Dev. Biol. 20, 395-402. doi: 10.1016/j.semcdb.2009.01.006

Blagov, P. S., Bi, W., Shedler, J., and Westen, D. (2012). The Shedler-Westen Assessment Procedure (SWAP): evaluating psychometric questions about its reliability, validity, and impact of its fixed score distribution. Assesment 19, 370-382. doi: 10.1177/1073191112436667

Blair, C., and Ursache, A. (2011). "A bidirectional model of executive functions and self-regulation," in Handbook of Self-Regulation: Research, Theory, and Applications, eds K. D. Vohs and R. F. Baumeister (New York, NY: The Guilford Press), 300-320.

Bornovalova, M. A., Lejuez, C. W., Daughters, S. B., Rosenthal, M. Z., and Lynch, T. R. (2005). Impulsivity as a common process across borderline personality and substance use disorders. Clin. Psychol. Rev. 25, 790-812. doi: 10.1016/j.cpr.2005.05.005

Brand, M., Roth-Bauer, M., Driessen, M., and Markowitsch, H. J. (2008). Executive functions and risky decision-making in patients with opiate dependence. Drug Alcohol Depend. 97, 64-72. doi: 10.1016/j.drugalcdep.2008.03.017

Brown, S. A., McGue, M., Maggs, J., Schulenberg, J., Hingson, R., Swartzwelder, S., et al. (2008). A developmental perspective on alcohol and youths 16 to 20 years of age. Pediatrics 121, S290-S310. doi: 10.1542/peds.2007-2243d

Carmody, D. P., Bennett, D. S., and Lewis, M. (2011). The effects of prenatal cocaine exposure and gender on inhibitory control and attention. Neurotoxicol. Teratol. 33, 61-68. doi: 10.1016/j.ntt.2010.07.004

Chambers, R. A., and Potenza, M. N. (2003). Neurodevelopment, impulsivity, and adolescent gambling. J. Gambl. Stud. 19, 53-84. doi: 10.1023/A:1021275130071

Chapman, K., Tarter, R. E., Kirisci, L., and Cornelius, M. D. (2007). Childhood neurobehavior disinhibition amplifies the risk of substance use disorder: interaction of parental history and prenatal alcohol exposure. J. Dev. Behav. Pediatr. 28, 219-224. doi: 10.1097/DBP.0b013e3180327907

Chassin, L., Curran, P. J., Hussong, A. M., and Colder, C. R. (1996). The relation of parent alcoholism to adolescent substance use: a longitudinal follow-up study. J. Abnorm. Psychol. 105, 70-80. doi: 10.1037/0021-843X.105.1.70

Chassin, L., Pitts, S. C., DeLucia, C., and Todd, M. (1999). A longitudinal study of children of alcoholics: predicting young adult substance use disorders, anxiety, and depression. J. Abnorm. Psychol. 108, 106-119. doi: 10.1037/0021843X.108.1.106

Chen, Y. Y., and Weitzman, E. R. (2005). Depressive symptoms, DSM-IV alcohol abuse and their comorbidity among children of problem drinkers in a national survey: effects of parent and child gender and parent recovery status. J. Stud. Alcohol 66, 66-73. doi: 10.15288/jsa.2005.66.66

Cone, E. J., Kato, K., and Hillsgrove, M. (1995). Cocaine excretion in the semen of drug users. J. Anal. Toxicol. 20, 139-140. doi: 10.1093/jat/20.2.139 
Connor, P. D., Sampson, P. D., Bookstein, F. L., Barr, H. M., and Streissguth, A. P. (2000). Direct and indirect effects of prenatal alcohol damage on executive function. Dev. Neuropsychol. 18, 331-354. doi: 10.1207/S1532694204Connor

Cooper, M. L., Wood, P. K., Orcutt, H. K., and Albino, A. (2003). Personality and the predisposition to engage in risky or problem behaviors during adolescence. J. Pers. Soc. Psychol. 84, 390-410. doi: 10.1037/0022-3514.84.2.390

Crean, A. J., and Bonduriansky, R. (2014). What is a paternal effect? Trends Ecol. Evol. 29, 554-559. doi: 10.1016/j.tree.2014.07.009

Cruz, R. P. (2005). Greatest source of wealth: Washington State's response to prenatal substance abuse. Gonzaga Low Rev. 41, 1-27. Available online at: http://blogs.gonzaga.edu/gulawreview/files/2011/02/Cruz.pdf

Cyr, J. J., McKenna-Foley, J. M., and Peacock, E. (1985). Factor structure of the SCL-90-R: is there one? J. Pers. Asses. 49, 571-578. doi: 10.1207/s15327752jpa4906_2

Daniel, J. Z., Hickman, M., MacLeod, J., Wiles, N., Lingford-Hughes, A., Farrell, M., et al. (2009). Is socioeconomic status in early life associated with drug use? A systematic review of the evidence. Drug Alcohol Rev. 28, 142-153. doi: 10.1111/j.1465-3362.2008.00042.x

Day, N. L., Leech, S. L., and Goldschmidt, L. (2011). The effects of prenatal marijuana exposure on delinquent behaviors are mediated by measures of neurocognitive functioning. Neurotoxicol. Teratol. 33, 129-136. doi: 10.1016/j.ntt.2010.07.006

Day, N. L., Richardson, G. A., Goldschmidt, L., Robles, N., Taylor, P. M., Stoffer, D. S., et al. (1994). Effect of prenatal marijuana exposure on the cognitive development of offspring at age three. Neurotoxicol. Teratol. 16, 169-175. doi: 10.1016/0892-0362(94)90114-7

Delaney-Black, V., Chiodo, L. M., Hannigan, J. H., Greenwald, M. K., Janisse, J., Patterson, G., et al. (2011). Prenatal and postnatal cocaine exposure predict teen cocaine use. Neurotoxicol. Teratol. 33, 110-119. doi: 10.1016/j.ntt.2010.06.011

Dennis, T., Bendersky, M., Ramsay, D., and Lewis, M. (2006). Reactivity and regulation in children prenatally exposed to cocaine. Dev. Psychol. 42, 688-697. doi: 10.1037/0012-1649.42.4.688

De Palo, F., Capra, N., Simonelli, A., Salcuni, S., and Di Riso, D. (2014). Parenting quality in drug-addicted mothers in a therapeutic mother-child community: the contribution of attachment and personality assessment. Front. Psychol. 5:1009. doi: 10.3389/fpsyg.2014.01009

Derogatis, L. (2011). Manuale di Somministrazione e Scoring. Adattamento Italiano di SCL-90-R. Firenze: Giunti, Organizzazioni Speciali.

Derogatis, L. R. (1994). SCL-90-R Symptom Checklist-90-R Administration, Scoring and Procedures Manual. Minneapolis, MN: National Computer Systems.

Dikmen, S. S., Corrigan, J. D., Levin, H. S., MacHamer, J., Stiers, W., and Weisskopf, M. G. (2009). Cognitive outcome following traumatic brain injury. J. Head Trauma Rehabil. 24, 430-438. doi: 10.1097/HTR.0b013e318 $1 \mathrm{c} 133 \mathrm{e} 9$

Edwards, E. P., Eiden, R. D., and Leonard, K. E. (2004). Impact of fathers' alcoholism and associated risk factors on parent-infant attachment stability from 12 to 18 months. Infant Ment. Health J. 25, 556-579. doi: 10.1002/imhj. 20027

Eiden, R. D., Chavez, F., and Leonard, K. (1999). Parent-infant interactions among families with alcoholic fathers. Dev. Psychopathol. 11, 745-762. doi: 10.1017/S0954579499002308

Eiden, R. D., Edwards, E. P., and Leonard, K. E. (2004). Predictors of effortful control among children of alcoholic and nonalcoholic fathers. J. Stud. Alcohol 65, 309-319. doi: 10.15288/jsa.2004.65.309

Eiden, R. D., and Leonard, K. E. (2000). Paternal alcoholism, parental psychopathology, and aggravation with infants. J. Subst. Abuse 11, 17-29. doi: 10.1016/S0899-3289(99)00016-4

Eiden, R. D., Schuetze, P., Colder, C. R., and Veira, Y. (2011). Maternal cocaine use and mother-toddler aggression. Neurotoxicol. Teratol. 33, 360-369. doi: 10.1016/j.ntt.2011.03.001

Elkins, I. J., King, S. M., McGue, M., and Iacono, W. G. (2006). Personality traits and the development of nicotine, alcohol, and illicit drug disorders: prospective links from adolescence to young adulthood. J. Abnorm. Psychol. 115, 26-39. doi: 10.1037/0021-843X.115.1.26

El-Sheikh, M., and Buckhalt, J. A. (2003). Parental problem drinking and children's adjustment: attachment and family functioning as moderators and mediators of risk. J. Fam. Psychol. 17, 510-520. doi: 10.1037/0893-3200.17.4.510
El-Sheikh, M., and Flanagan, E. (2001). Parental problem drinking and children's adjustment: family conflict and parental depression as mediators and moderators of risk. J. Abnorm. Child Psychol. 29, 417-432. doi: 10.1023/A:1010447503252

European Monitoring Centre for Drugs and Drug Addiction (EMCDDA) (2012). Pregnancy, Childcare and the Family: Key Issues for Europe's Response to Drugs. Available online at: http://www.emcdda.europa.eu/publications/ selected-issues/children

Engeland, A., Bjørge, T., Daltveit, A. K., Skurtveit, S., Vangen, S., Vollset, S. E., et al. (2013). Effects of preconceptional paternal drug exposure on birth outcomes: cohort study of 340000 pregnancies using Norwegian populationbased databases. Br. J. Clin. Pharmacol. 75, 1134-1141. doi: 10.1111/j.13652125.2012.04426.x

Enoch, M. A. (2011). The role of early life stress as a predictor for alcohol and drug dependence. Psychopharmacology 214, 17-31. doi: 10.1007/s00213-010-1916-6

Ersche, K. D., Clark, L., London, M., Robbins, T. W., and Sahakian, B. J. (2006). Profile of executive and memory function associated with amphetamine and opiate dependence. Neuropsychopharmacology 31, 1036-1047. doi: 10.1038/sj.npp.1300889

Evans, G. W., and Schamberg, M. A. (2009). Childhood poverty, chronic stress, and adult working memory. Proc. Natl. Acad. Sci. U.S.A. 106, 6545-6549. doi: 10.1073/pnas.0811910106

Eyler, F. D., Warner, T. D., Behnke, M., Hou, W., Wobie, K., and Garvan, C. W. (2009). Executive functioning at ages 5 and 7 years in children with prenatal cocaine exposure. Dev. Neurosci. 31, 121-136. doi: 10.1159/000207500

Fals-Stewart, W., Kelley, M. L., Fincham, F. D., Golden, J., and Logsdon, T. (2004). Emotional and behavioral problems of children living with drugabusing fathers: comparisons with children living with alcohol-abusing and non-substance-abusing fathers. J. Fam. Psychol. 18, 319-330. doi: 10.1037/08933200.18.2.319

Farah, M. J., Betancourt, L., Shera, D. M., Savage, J. H., Giannetta, J. M., Brodsky, N. L., et al. (2008). Environmental stimulation, parental nurturance and cognitive development in humans. Dev. Sci. 11, 793-801. doi: 10.1111/j.14677687.2008.00688.x

Farah, M. J., Shera, D. M., Savage, J. H., Betancourt, L., Giannetta, J. M., Brodsky, N. L., et al. (2006). Childhood poverty: specific associations with neurocognitive development. Brain Res. 1110, 166-174. doi: 10.1016/j.brainres.2006.06.072

Fishbein, D. H., Krupitsky, E., Flannery, B. A., Langevin, D. J., Bobashev, G., Verbitskaya, E., et al. (2007). Neurocognitive characterizations of Russian heroin addicts without a significant history of other drug use. Drug Alcohol Depend. 90, 25-38. doi: 10.1016/j.drugalcdep.2007.02.015

Fisher, P. A., and Gunnar, M. R. (2010). "Early life stress as a risk factor for disease in adulthood", in The Impact of Early Life Trauma on Health and Disease, eds R. A. Lanius, E. Vermetten, and C. Pain (Cambridge, UK: University Press), 133-141.

Fisher, P. A., Lester, B. M., DeGarmo, D. S., LaGasse, L. L., Lin, H., Shankaran, S., et al. (2011). The combined effects of prenatal drug exposure and early adversity on neurobehavioral disinhibition in childhood and adolescence. Dev. Psychopathol. 23, 777-788. doi: 10.1017/S0954579411000290

Ford, J. D., and Smith, S. F. (2008). Complex posttraumatic stress disorder in trauma-exposed adults receiving public sector outpatient substance abuse disorder treatment. Addict. Res. Theory 16, 193-203. doi: $10.1080 / 16066350701615078$

Frank, D. A., Rose-Jacobs, R., Beeghly, M., Wilbur, M., Bellinger, D., and Cabral, H. (2005). Level of prenatal cocaine exposure and 48-month IQ: importance of preschool enrichment. Neurotoxicol. Teratol. 27, 15-28. doi: 10.1016/j.ntt.2004.09.003

Fried, P. A., and Smith, A. M. (2001). A literature review of the consequences of prenatal marihuana exposure: an emerging theme of a deficiency in aspects of executive function. Neurotoxicol Teratol. 23, 1-11. doi: 10.1016/S08920362(00)00119-7

Giancola, P. R., and Tarter, R. E. (1999). Executive cognitive functioning and risk for substance abuse. Psychol. Sci. 10, 203-205. doi: 10.1111/1467-9280.00135

Gibb, B. E., Wheeler, R., Alloy, L. B., and Abramson, L. Y. (2001). Emotional, physical, and sexual maltreatment in childhood versus adolescence and personality dysfunction in young adulthood. J. Pers. Disord. 15, 505-511. doi: 10.1521/pedi.15.6.505.19194 
Glantz, M. D., and Chambers, J. C. (2006). Prenatal drug exposure effects on subsequent vulnerability to drug abuse. Dev. Psychopathol. 18, 893-922. doi: 10.1017/S0954579406060445

Goldman, D., Oroszi, G., and Ducci, F. (2005). The genetics of addictions: uncovering the genes. Nat. Rev. Genet. 6, 521-532. doi: 10.1038/nrg1635

Goldschmidt, L., Richardson, G. A., Willford, J., and Day, N. L. (2008). Prenatal marijuana exposure and intelligence test performance at age 6. J. Am. Acad. Child Adolesc. Psychiatry 47, 254-263. doi: 10.1097/CHI.0b013e318160b3f0

Goler, N. C., Armstrong, M. A., Osejo, V. M., Hung, Y. Y., Haimowitz, M., and Caughey, A. B. (2012). Early start: a cost-beneficial perinatal substance abuse program. Obstet. Gynecol. 119, 102-110. doi: 10.1097/AOG.0b013e31823d427d

Grant, T. M., Brown, N. N., Dubovsky, D., Sparrow, J., and Ries, R. (2013). The impact of prenatal alcohol exposure on addiction treatment. J. Addict. Med. 7, 87-95. doi: 10.1097/ADM.0b013e31828b47a8

Griffith, D. R., Azuma, S. D., and Chasnoff, I. J. (1994). Three-year outcome of children exposed prenatally to drugs. J. Am. Acad. Child Adolesc. Psychiatry 33, 20-27. doi: 10.1097/00004583-199401000-00004

Guttmacher Institute (2015). Substance Abuse during Pregnancy. State Policies in Brief. Available online at: https://www.guttmacher.org/sites/default/files/pdfs/ spibs/spib_SADP.pdf

Hackman, D. A., and Farah, M. J. (2009). Socioeconomic status and the developing brain. Trends Cogn. Sci. 13, 65-73. doi: 10.1016/j.tics.2008.11.003

Hans, S. L. (2002). Studies of prenatal exposure to drugs. Focusing on parental care of children. Neurotoxicol. Teratol. 24, 329-337. doi: 10.1016/S08920362(02)00195-2

Hanson, K. L., Winward, J. L., Schweinsburg, A. D., Medina, K. L., Brown, S. A., and Tapert, S. F. (2010). Longitudinal study of cognition among adolescent marijuana users over three weeks of abstinence. Addict. Behav. 35, 970-976. doi: 10.1016/j.addbeh.2010.06.012

Henry, J., Sloane, M., and Black-Pond, C. (2007). Neurobiology and neurodevelopmental impact of childhood traumatic stress and prenatal alcohol exposure. Lang. Speech Hear. Serv. Sch. 38, 99-108. doi: 10.1044/0161-1461(2007/010)

Hicks, B. M., Iacono, W. G., and McGue, M. (2012). Index of the transmissible common liability to addiction: heritability and prospective associations with substance abuse and related outcomes. Drug Alcohol Depend. 123, S18-S23. doi: 10.1016/j.drugalcdep.2011.12.017

Hinrichs, J., DeFife, J., and Westen, D. (2011). Personality subtypes in adolescent and adult children of alcoholics: a two part study. J. Nerv. Ment. Dis. 199, 487-498. doi: 10.1097/NMD.0b013e3182214268

Hurt, H., Betancourt, L. M., Malmud, E. K., Shera, D. M., Giannetta, J. M., Brodsky, N. L., et al. (2009). Children with and without gestational cocaine exposure: a neurocognitive systems analysis. Neurotoxicol. Teratol. 31, 334-341. doi: 10.1016/j.ntt.2009.08.002

Hurt, H., Giannetta, J. M., Korczykowski, M., Hoang, A., Tang, K. Z., Betancourt, L., et al. (2008). Functional magnetic resonance imaging and working memory in adolescents with gestational cocaine exposure. J. Paediatr. 152, 371-377. doi: 10.1016/j.jpeds.2007.08.006

Hussong, A., Bauer, D., and Chassin, L. (2008). Telescoped trajectories from alcohol initiation to disorder in children of alcoholic parents. J. Abnorm. Psychol. 117, 63-78. doi: 10.1037/0021-843X.117.1.63

Hussong, A. M., Curran, P. J., and Chassin, L. (1998). Pathways of risk for accelerated heavy alcohol use among adolescent children of alcoholic parents. J. Abnorm. Child Psychol. 26, 453-466.

Hussong, A. M., Huang, W., Serrano, D., Curran, P. J., and Chassin, L. (2012). Testing whether and when parent alcoholism uniquely affects various forms of adolescent substance use. J. Abnorm. Child Psychol. 40, 1265-1276. doi: $10.1007 / \mathrm{s} 10802-012-9662-3$

Jacobson, S. W., Jacobson, J. L., Sokol, R. J., Martier, S. S., and Chiodo, L. M. (1996). New evidence for neurobehavioral effects of in utero cocaine exposure. J. Pediatr. 129, 581-590. doi: 10.1016/S0022-3476(96)70124-5

Jernigan, D. H. (2001). Global Status Report: Alcohol and Young People. Geneva: World Health Organization.

Johnston, L. D., O’Malley, P. M., Bachman, J. G., and Schulenberg, J. E. (2010). Monitoring the Future national survey results on drug use, 1975-2009. Volume II: College students and adults ages 19-50. NIH Publication No. 10-7585. Bethesda, MD: National Institute on Drug Abuse.

Jutras-Aswad, D., DiNieri, J. A., Harkany, T., and Hurd, Y. L. (2009). Neurobiological consequences of maternal cannabis on human fetal development and its neuropsychiatric outcome. Eur. Arch. Psychiatry Clin. Neurosci. 259, 395-412. doi: 10.1007/s00406-009-0027-z

Kearney, C. A., Wechsler, A., Kaur, H., and Lemos-Miller, A. (2010). Posttraumatic stress disorder in maltreated youth: a review of contemporary research and thought. Clin. Child Fam. Psychol. Rev. 13, 46-76. doi: 10.1007/s10567-0090061-4

Kerns, K. A., Don, A., Matee, C. A., and Streissugth, A. P. (1997). Cognitive deficits in nontreated adults with fetal alcohol syndrome. J. Learn. Disabil. 30, 658-693. doi: $10.1177 / 002221949703000612$

Killinger, C. E., Robinson, S., and Stanwood, G. D. (2012). Subtle biobehavioral effects produced by paternal cocaine exposure. Synapse 66, 902-908. doi: $10.1002 /$ syn. 21582

Kliewer, W., and Murrelle, L. (2007). Risk and protective factors for adolescent substance use: findings from a study in selected Central American countries. J. Adolesc. Health 40, 448-455. doi: 10.1016/j.jadohealth.2006.11.148

Klonoff-Cohen, H., and Lam-Kruglick, P. (2001). Maternal and paternal recreational drug use and sudden infant death syndrome. Arch. Pediatr. Adolesc. Med. 155, 765-770. doi: 10.1001/archpedi.155.7.765

Kodituwakku, P. W., Handmaker, N. S., Cutler, S. K., Weathersby, E. K., and Handmaker, S. D. (1995). Specific impairments in self-regulation in children exposed to alcohol prenatally. Alcohol. Clin. Exp. Res. 19, 1558-1564. doi: 10.1111/j.1530-0277.1995.tb01024.x

Kokkevi, A., Stefanis, N., Anastasopoulou, E., and Kostogianni, C. (1998). Personality disorders in drug abusers: prevalence and their association with AXIS I disorders as predictors of treatment retention. Addict. Behav. 23, 841-853. doi: 10.1016/S0306-4603(98)00071-9

Konijnenberg, C., and Melinder, A. (2011). Prenatal exposure to methadone and buprenorphine: a review of the potential effects on cognitive development. Child Neuropsychol. 17, 495-519. doi: 10.1080/09297049.2011.553591

Kopera-Frye, K., Dehaene, S., and Streissguth, A. P. (1996). Impairments of number processing induced by prenatal alcohol exposure. Neuropsychologia 34, 1187-1196. doi: 10.1016/0028-3932(96)00043-7

Krueger, R. F., Markon, K. E., Patrick, C. J., Benning, S. D., and Kramer, M. D. (2007). Linking antisocial behavior, substance use, and personality: an integrative quantitative model of the adult externalizing spectrum. J. Abnorm. Psychol. 116, 645-666. doi: 10.1037/0021-843X.116.4.645

Langås, A. M., Malt, U. F., and Opjordsmoen, S. (2012). In-depth study of personality disorders in first-admission patients with substance use disorders. BMC Psychiatry. 12:180. doi: 10.1186/1471-244X-12-180

Leech, S. L., Richardson, G. A., Goldschmidt, L., and Day, N. L. (1999). Prenatal substance exposure: effects on attention and impulsivity of 6-year-olds. Neurotoxicol. Teratol. 21, 109-118. doi: 10.1016/S0892-0362(98)00042-7

Lester, B. M., LaGasse, L. L., Shankaran, S., Bada, H. S., Bauer, C. R., Lin, R., et al. (2010). Prenatal cocaine exposure related to cortisol stress reactivity in 11-year-old children. J. Pediatr. 157, 288-295. doi: 10.1016/j.jpeds.2010.02.039

Lester, B. M., Lin, H., DeGarmo, D. S., Fisher, P. A., LaGasse, L. L., Levine, T. P., et al. (2012). Neurobehavioral disinhibition predicts initiation of substance use in children with prenatal cocaine exposure. Drug Alcohol Depend. 126, 80-86. doi: 10.1016/j.drugalcdep.2012.04.014

Lewis, B. A., Kirchner, H. L., Short, E. J., Minnes, S., Weishampel, P., Satayathum, S., et al. (2007). Prenatal cocaine and tobacco effects on children's language trajectories. Pediatrics 120, e78-e85. doi: 10.1542/peds.2006-2563

Lewis, E. E., Dozier, M., Ackerman, J., and Sepulveda-Kozakowski, S. (2007). The effect of placement instability on adopted children's inhibitory control abilities and oppositional behavior. Dev. Psychol. 43, 1415-1427. doi: 10.1037/00121649.43.6.1415

Li, Z., Coles, C. D., Lynch, M. E., Hamann, S., Peltier, S., LaConte, S., et al. (2009). Prenatal cocaine exposure alters emotional arousal regulation and its effects on working memory. Neurotoxicol. Teratol. 31, 342-348. doi: 10.1016/j.ntt.2009.08.005

Lingiardi, V., Shedler, J., and Gazzillo, F. (2006). Assessing personality change in psychotherapy with the SWAP-200: a case study. J. Pers. Assess. 86, 23-32. doi: 10.1207/s15327752jpa8601_04

Lipina, S. J., Martelli, M. I., and Colombo, J. A. (2005). Performance on the Anot-B task of Argentinean infants from unsatisfied and satisfied basic needs homes. Interam. J. Psychol. 39, 49-60. Available online at: http://www.psicorip. org/Resumos/PerP/RIP/RIP036a0/RIP03906.pdf

Mackesy-Amiti, M. E., Donenberg, G. R., and Ouellet, L. J. (2012). Prevalence of psychiatric disorders among young injection drug users. 
Drug Alcohol Depend. 124, 70-78. doi: 10.1016/j.drugalcdep.2011. 12.012

Malone, S. M., Taylor, J., Marmorstein, N. R., McGue, M., and Iacono, W. G. (2004). Genetic and environmental influences on antisocial behavior and alcohol dependence from adolescence to early adulthood. Dev. Psychopathol. 16, 943-966. doi: 10.1017/s0954579404040088

Marin-Avellan, L. E., McGauley, G., Campbell, C., and Fonagy, P. (2005). Using the SWAP-200 in a personality-disordered forensic population: is it valid, reliable and useful? Crim. Behav. Ment. Health 15, 28-45. doi: 10.1002/cbm.35

Mattson, S. N., and Roebuck, T. M. (2002). Acquisition and retention of verbal and nonverbal information in children with heavy prenatal alcohol exposure. Alcohol. Clin. Exp. Res. 26, 875-882. doi: 10.1111/j.1530-0277.2002.tb02617.x

Maurage, P., Heeren, A., and Pesenti, M. (2013). Does chocolate consumption really boost Nobel award chances? The peril of over-interpreting correlations in health studies. J. Nutr. 143, 931-933. doi: 10.3945/jn.113.174813

May, P. A., Tabachnick, B. G., Gossage, J. P., Kalberg, W. O., Marais, A. S., Robinson, L. K., et al. (2013). Maternal factors predicting cognitive and behavioral characteristics of children with fetal alcohol spectrum disorders. J. Dev. Behav. Pediatr. 34, 314-325. doi: 10.1097/DBP.0b013e3182905587

Mayes, L. C. (2002). A behavioral teratogenic model of the impact of prenatal cocaine exposure on arousal regulatory systems. Neurotoxicol. Teratol. 24, 385-395. doi: 10.1016/S0892-0362(02)00200-3

Mayes, L. C., Molfese, D. L., Key, A. P., and Hunter, N. C. (2005). Event-related potentials in cocaine-exposed children during a Stroop task. Neurotoxicol. Teratol. 27, 797-813. doi: 10.1016/j.ntt.2005.05.011

McClelland, M. M., Cameron, C. E., Wanless, S. B., and Murray, A. (2007). "Executive function, behavioral self-regulation, and social-emotional competence", in Contemporary Perspectives on Social Learning in Early Childhood Education, eds O. N. Saracho and B. Spodek (Charlotte, NC: IAP), 113-137.

McGue, M., and Iacono, W. G. (2008). The adolescent origins of substance use disorders. Int. J. Methods Psych. Res. 17, 30-38. doi: 10.1002/mpr.242

McNamee, R. L., Dunfee, K. L., Luna, B., Clark, D. B., Eddy, W. F., and Tarter, R. E. (2008). Brain activation, response inhibition, and increased risk for substance use disorder. Alcohol. Clin. Exp. Res. 32, 405-413. doi: 10.1111/j.1530-0277.2007.00604.x

Melchior, M., Choquet, M., Le Strat, Y., Hassler, C., and Gorwood, P. (2011). Parental alcohol dependence, socioeconomic disadvantage and alcohol and cannabis dependence among young adults in the community. Eur. Psychiatry 26, 13-17. doi: 10.1016/j.eurpsy.2009.12.011

Meyers, J. L., and Dick, D. M. (2010). Genetic and environmental risk factors for adolescent-onset substance use disorders. Child Adolesc. Psychiatr. Clin. N. Am. 19, 465-477. doi: 10.1016/j.chc.2010.03.013

Mezzacappa, E. (2004). Alerting, orienting, and executive attention: developmental properties and sociodemographic correlates in an epidemiological sample of young, urban children. Child Dev. 75, 1373-1386. doi: 10.1111/j.14678624.2004.00746.x

Minnes, S., Singer, L. T., Min, M. O., Lang, A. M., Ben-Harush, A., Short, E., et al. (2014). Comparison of 12-year-old children with prenatal exposure to cocaine and non-exposed controls on caregiver ratings of executive function. J. Youth Adolesc. 43, 53-69. doi: 10.1007/s10964-013-9927-3

Moilanen, K. L., Shaw, D. S., Dishion, T. J., Gardner, F., and Wilson, M. (2010). Predictors of longitudinal growth in inhibitory control in early childhood. Soc. Dev. 19, 326-347. doi: 10.1111/j.1467-9507.2009.00536.x

Mondini, S., Mapelli, D., Vestri, A., Arcara, A., and Bisiacchi, P. S. (2011). Esame Neuropsicologico breve 2. Milano: Raffaello Cortina Editore.

Mondini, S., Mapelli, D., Vestri, A., and Bisiacchi, P. S. (2003). Esame Neuropsicologico Breve. Milano: Raffaello Cortina Editore.

Morgan, P. T., Desai, R. A., and Potenza, M. N. (2010). Gender-related influences of parental alcoholism on the prevalence of psychiatric illnesses: analysis of the national epidemiologic survey on alcohol and related conditions. Alcohol. Clin. Exp. Res. 34, 1759-1767. doi: 10.1111/j.1530-0277.2010.01263.x

Nigg, J. T., Hinshaw, S. P., and Huang-Pollack, C. (2006). "Disorders of attention and impulse regulation," in Developmental Psychopathology. Vol. 3: Risk, Disorder, and Adaptation, eds D. Cicchetti and D. Cohen (New York, NY: Wiley), 358-403.

Noble, K. G., McCandliss, B. D., and Farah, M. J. (2007). Socioeconomic gradients predict individual differences in neurocognitive abilities. Dev. Sci. 10, 464-480. doi: $10.1111 /$ j.1467-7687.2007.00600.x
Noble, K. G., Norman, M. F., and Farah, M. J. (2005). Neurocognitive correlates of socioeconomic status in kindergarten children. Dev. Sci. 8, 74-87. doi: 10.1111/j.1467-7687.2005.00394.x

Noland, J. S., Singer, L. T., Arendt, R. E., Minnes, S., Short, E. J., and Bearer, C. F. (2003). Executive functioning in preschool-age children prenatally exposed to alcohol, Cocaine, and Marijuana. Alcohol. Clin. Exp. Res. 27, 647-656. doi: 10.1111/j.1530-0277.2003.tb04401.x

Noland, J. S., Singer, L. T., Short, E. J., Minnes, S., Arendt, R. E., Kirchner, H. L., et al. (2005). Prenatal drug exposure and selective attention in preschoolers. Neurotoxicol. Teratol. 27, 429-438. doi: 10.1016/j.ntt.2005.02.001

Obot, I. S., Wagner, F. A., and Anthony, J. C. (2001). Early onset and recent drug use among children of parents with alcohol problems: data from a national epidemiologic survey. Drug Alcohol Depend. 65, 1-8. doi: 10.1016/S03768716(00)00239-8

O’Brien, J. W., and Hill, S. Y. (2014). Effects of prenatal alcohol and cigarette exposure on offspring substance use in multiplex, alcohol-dependent families. Alcohol. Clin. Exp. Res. 38, 2952-2961. doi: 10.1111/acer.12569

O'Connor, M. J., and Paley, B. (2009). Psychiatric conditions associated with prenatal alcohol exposure. Dev. Dis. Res. Rev. 15, 225-234. doi: 10.1002/ddrr.74

Olson, H. C., Feldman, J. J., Streissguth, A. P., Sampson, P. D., and Bookstein, F. L. (1998). Neuropsychological deficits in adolescents with fetal alcohol syndrome: clinical findings. Alcohol. Clin. Exp. Res. 22, 1998-2012. doi: 10.1097/00000374199812000-00016

Olson, H. C., Sampson, P. D., Barr, H., Streissguth, A. P., and Bookstein, F. L. (1992). Prenatal exposure to alcohol and school problems in late childhood: a longitudinal prospective study. Dev. Psychopathol. 4, 341-341. doi: 10.1017/S0954579400000821

Pears, K. C., Kim, H. K., and Fisher, P. A. (2008). Psychosocial and cognitive functioning of children with specific profiles of maltreatment. Child Abuse Negl. 32, 958-971. doi: 10.1016/j.chiabu.2007.12.009

Posner, M. I., Rothbart, M. K., Sheese, B. E., and Voelker, P. (2014). Developing attention: behavioral and brain mechanisms. Adv. Neurosci. 2014:405094. doi: $10.1155 / 2014 / 405094$

Prunas, A., Sarno, I., Preti, E., Madeddu, F., and Perugini, M. (2012). Psychometric properties of the Italian version of the SCL-90-R: a study on a large community sample. Eur. Psychiatry 27, 591-597. doi: 10.1016/j.eurpsy.2010.break12.006

Putnam, F. W. (2006). The impact of trauma on child development. Juvenile Fam. Court J. 57, 1-11. doi: 10.1111/j.1755-6988.2006.tb00110.x

Rao, H., Wang, J., Giannetta, J., Korczykowski, M., Shera, D., Avants, B. B., et al. (2007). Altered resting cerebral blood flow in adolescents with in utero cocaine exposure revealed by perfusion functional MRI. Pediatrics 120, e1245-e1254. doi: 10.1542/peds.2006-2596

Rasmussen, C. (2005). Executive functioning and working memory in fetal alcohol spectrum disorder. Alcohol. Clin. Exp. Res. 29, 1359-1367. doi: 10.1097/01.alc.0000175040.91007.d0

Rasmussen, C., Horne, K., and Witol, A. (2006). Neurobehavioral functioning in children with fetal alcohol spectrum disorder. Child Neuropsychol. 12, 453-468. doi: 10.1080/09297040600646854

Richardson, G. A., Goldschmidt, L., Leech, S., and Willford, J. (2011). Prenatal cocaine exposure: effects on mother-and teacher-rated behavior problems and growth in school-age children. Neurotoxicol. Teratol. 33, 69-77. doi: 10.1016/j.ntt.2010.06.003

Richardson, G. A., Ryan, C., Willford, J., Day, N. L., and Goldschmidt, L. (2002). Prenatal alcohol and marijuana exposure: effects on neuropsychological outcomes at 10 years. Neurotoxicol. Teratol. 24, 309-320. doi: 10.1016/S08920362(02)00193-9

Riley, E. P., and McGee, C. L. (2005). Fetal alcohol spectrum disorders: an overview with emphasis on changes in brain and behavior. Exp. Biol. Med. 230, 357-365. Available online at: http://www.thearcnevada.orgwww.thearcnevada.org/file/ documents_initiatives_fasd-prevention-project/Riley-et-al.-2005.pdf

Rose-Jacobs, R., Soenksen, S., Appugliese, D. P., Cabral, H. J., Richardson, M. A., Beeghly, M., et al. (2011). Early adolescent executive functioning, intrauterine exposures and own drug use. Neurotoxicol. Teratol. 33, 379-392. doi: 10.1016/j.ntt.2011.02.013

Rose-Jacobs, R., Waber, D., Beeghly, M., Cabral, H., Appugleise, D., Heeren, T., et al. (2009). Intrauterine cocaine exposure and executive functioning in middle childhood. Neurotoxicol. Teratol. 31, 159-168. doi: 10.1016/j.ntt.2008.12.002

Rosenkranz, S. E., Muller, R. T., and Henderson, J. L. (2014). The role of complex PTSD in mediating childhood maltreatment and substance abuse severity 
among youth seeking substance abuse treatment. Psychol. Trauma 6, 25-33. doi: $10.1037 / \mathrm{a} 0031920$

Rubes, J., Lowe, X., Moore, D., Perreault, S., Slott, V., Evenson, D., et al. (1998). Smoking cigarettes is associated with increased sperm disomy in teenage men. Fertil. Steril. 70, 715-723. doi: 10.1016/S0015-0282(98)00261-1

Samhsa Office of Applied Studies (SAMHSA) (2009). National Survey on Drug Use and Health: Lifetime, Pas Year, and Past Month Illicit Drug Use, by Selected Age Categories and Gender. Available online at: http://www.gmhc.org/files/editor/ file/a_pa_nat_drug_use_survey.pdf

Sarno, I., Preti, E., Prunas, A., and Madeddu, F. (2011). SCL-90-R Symptom Checklist-90-R Adattamento Italiano. Firenze: Giunti, Organizzazioni Speciali.

Savage, J., Brodsky, N. L., Malmud, E., Giannetta, J. M., and Hurt, H. (2005). Attentional functioning and impulse control in cocaine-exposed and control children at age ten years. J. Dev. Behav. Pediatr. 26, 42-47.

Schmid, B., Blomeyer, D., Becker, K., Treutlein, J., Zimmermann, U. S., Buchmann, A. F., et al. (2009). Genetic study: the interaction between the dopamine transporter gene and age at onset in relation to tobacco and alcohol use among 19-year-olds. Addict. Biol. 14, 489-499. doi: 10.1111/j.1369-1600.2009. 00171.x

Shedler, J., and Westen, D. (1998). Refining the measurement of Axis II: a qsort procedure for assessing personality pathology. Assessment 5, 333-353. doi: $10.1177 / 107319119800500403$

Shedler, J., Westen, D., and Lingiardi, V. (2014). La Valutazione Della Personalità Con La SWAP-200. Milano: Raffaello Cortina Editore.

Sheinkopf, S. J., Lester, B. M., Sanes, J. N., Eliassen, J. C., Hutchison, E. R., Seifer, R., et al. (2009). Functional MRI and response inhibition in children exposed to cocaine in utero. Dev. Neurosci. 31, 159-166. doi: 10.1159/000 207503

Singer, L. T., Minnes, S., Short, E., Arendt, R., Farkas, K., Lewis, B., et al. (2004). Cognitive outcomes of preschool children with prenatal cocaine exposure. JAMA 291, 2448-2456. doi: 10.1001/jama.291.20.2448

Singer, L. T., Nelson, S., Short, E., Min, M. O., Lewis, B., Russ, S., et al. (2008). Prenatal cocaine exposure: drug and environmental effects at 9 years. J. Pediatr. 153, 105-111. doi: 10.1016/j.jpeds.2008.01.001

Smith, A. M., Fried, P. A., Hogan, M. J., and Cameron, I. (2006). Effects of prenatal marijuana on visuospatial working memory: an fMRI study in young adults. Neurotoxicol. Teratol. 28, 286-295. doi: 10.1016/j.ntt.2005.12.008

Solowij, N., and Pesa, N. (2010). Cognitive abnormalities and cannabis use. Rev. Bras. Psiquiatr. 32, 531-540. doi: 10.1590/S1516-444620100005 00006

Stocco, P., Simonelli, A., Capra, N., and De Palo, F. (2012). "Research and intervention for drug-addicted mothers and their children: new perspectives," in Addictions - From Pathophysiology to Treatment, ed D. Belin (InTech), 425-452.

Stone, A. L., Becker, L. G., Huber, A. M., and Catalano, R. F. (2012). Review of risk and protective factors of substance use and problem use in emerging adulthood. Addict. Behav. 37, 747-775. doi: 10.1016/j.addbeh.2012.02.014

Strathearn, L., and Mayes, L. C. (2010). Cocaine addiction in mothers: potential effects on maternal care and infant development. Ann. N.Y. Acad. Sci. 1187, 172-183. doi: 10.1111/j.1749-6632.2009.05142.x

Tapert, S. F., and Brown, S. A. (2000). Substance dependence, family history of alcohol dependence and neuropsychological functioning in adolescence. Addiction 95, 1043-1053. doi: 10.1046/j.1360-0443.2000.95710436.x

Tapert, S. F., Granholm, E., Leedy, N. G., and Brown, S. A. (2002). Substance use and withdrawal: neuropsychological functioning over 8 years in youth. J. Int. Neuropsychol. Soc. 8, 873-883. doi: 10.1017/S13556177028 70011

Taplin, C., Saddichha, S., Li, K., and Krausz, M. R. (2014). Family history of alcohol and drug abuse, childhood trauma, and age of first drug injection. Subst. Use Misuse 49, 1311-1316. doi: 10.3109/10826084.2014.901383

Tarter, R. E., Kirisci, L., Habeych, M., Reynolds, M., and Vanyukov, M. (2004). Neurobehavior disinhibition in childhood predisposes boys to substance use disorder by young adulthood: direct and mediated etiologic pathways. Drug Alcohol Depend. 73, 121-132. doi: 10.1016/j.drugalcdep.2003. 07.004

Tarter, R. E., Mezzich, A. C., Hsieh, Y. C., and Parks, S. M. (1995). Cognitive capacity in female adolescent substance abusers. Drug Alcohol Depend. 39, 15-21. doi: 10.1016/0376-8716(95)01129-M
Thompson, B. L., Levitt, P., and Stanwood, G. D. (2009). Prenatal exposure to drugs: effects on brain development and implications for policy and education. Nat. Rev. Neurosci. 10, 303-312. doi: 10.1038/nrn2598

Tonmyr, L., Thornton, T., Draca, J., and Wekerle, C. (2010). A review of childhood maltreatment and adolescent substance use relationship. Curr. Psychiatry Rev. 6, 223-234. doi: 10.2174/157340010791792581

van der Kolk, B. A., Roth, S., Pelcovitz, D., Sunday, S., and Spinazzola, J. (2005). Disorders of extreme stress: the empirical foundation of a complex adaptation to trauma. J. Trauma. Stress 18, 389-399. doi: 10.1002/jts.20047

Van Voorst, W. A., and Quirk, S. W. (2003). Are relations between parental history of alcohol problems and changes in drinking moderated by positive expectancies?. Alcohol. Clin. Exp. Res. 27, 25-30. doi: 10.1111/j.15300277.2003.tb02716.x

Vaske, J., Beaver, K. M., Wright, J. P., Boisvert, D., and Schnupp, R. (2009). An interaction between DAT1 and having an alcoholic father predicts serious alcohol problems in a sample of males. Drug Alcohol Depend. 104, 17-22. doi: 10.1016/j.drugalcdep.2009.01.020

Velez, M. L., Jansson, L. M., Montoya, I. D., Schweitzer, W., Golden, A., and Svikis, D. (2004). Parenting knowledge among substance abusing women in treatment. J. Subst. Abuse Treat. 27, 215-222. doi: 10.1016/j.jsat.2004.07.004

Verdejo-García, A., Perales, J. C., and Pérez-García, M. (2007). Cognitive impulsivity in cocaine and heroin polysubstance abusers. Addict. Behav. 32, 950-966. doi: 10.1016/j.addbeh.2006.06.032

Warner, T. D., Behnke, M., Eyler, F. D., Padgett, K., Leonard, C., Hou, W., et al. (2006). Diffusion tensor imaging of frontal white matter and executive functioning in cocaine-exposed children. Pediatrics 118, 2014-2024. doi: 10.1542/peds.2006-0003

Warner, T. D., Behnke, M., Eyler, F. D., and Szabo, N. J. (2011). Early adolescent cocaine use as determined by hair analysis in a prenatal cocaine exposure cohort. Neurotoxicol. Teratol. 33, 88-99. doi: 10.1016/j.ntt.2010.07.003

Westen, D., and Muderrisoglu, S. (2003). Reliability and Validity of Personality Disorder Assessment using a Systematic Clinical Interview. Atlanta, GA: Emory University.

Westen, D., and Shedler, J. (1999a). Revising and assessing Axis II, Part I: developing a clinically and empirically valid assessment method. Am. J. Psychiatry 156, 258-272.

Westen, D., and Shedler, J. (1999b). Revising and assessing Axis II, Part 2: toward an empirically based and clinically useful classification of personality disorders. Am. J. Psychiatry 156, 273-285.

Westen, D., and Weinberger, J. (2004). When clinical description becomes statistical prediction. Am. Psychol. 59, 595-613. doi: 10.1037/0003-066X.59.7.595

Willford, J. A., Richardson, G. A., Leech, S. L., and Day, N. L. (2004). Verbal and visuospatial learning and memory function in children with moderate prenatal alcohol exposure. Alcohol. Clin. Exp. Res. 28, 497-507. doi: 10.1097/01.ALC.0000117868.97486.2D

Willford, J. A., Richardson, G. A., Leech, S. L., Ryan, C. M., Goldschmidt, L., and Day, N. L. (2001). Executive function in adolescents with moderate prenatal alcohol exposure. Alcohol. Clin. Exp. Res. 25, 122A.

Woon, F. L., and Hedges, D. W. (2008). Hippocampal and amygdala volumes in children and adults with childhood maltreatment-related posttraumatic stress disorder: a meta-analysis. Hippocampus 18, 729-736. doi: 10.1002/hipo.20437

Young, R. M., Lawford, B. R., Nutting, A., and Noble, E. P. (2004). Advances in molecular genetics and the prevention and treatment of substance misuse: implications of association studies of the A 1 allele of the D 2 dopamine receptor gene. Addict. Behav. 29, 1275-1294. doi: 10.1016/j.addbeh.2004.06.012

Conflict of Interest Statement: The authors declare that the research was conducted in the absence of any commercial or financial relationships that could be construed as a potential conflict of interest.

Copyright (C) 2016 Parolin, Simonelli, Mapelli, Sacco and Cristofalo. This is an openaccess article distributed under the terms of the Creative Commons Attribution License (CC BY). The use, distribution or reproduction in other forums is permitted, provided the original author(s) or licensor are credited and that the original publication in this journal is cited, in accordance with accepted academic practice. No use, distribution or reproduction is permitted which does not comply with these terms. 